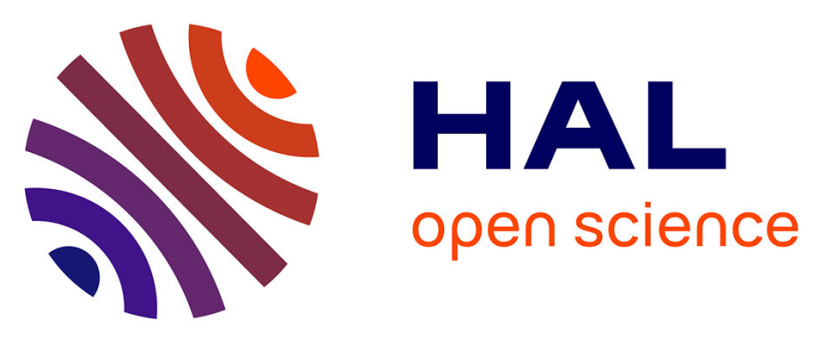

\title{
Experimental Investigations on Noise Shielding: Dependency on Reference Noise Source and Testing Environment
}

Karl-Stéphane Rossignol, Jan Werner Delfs, Michael Mössner, Denis Gély, Jean Bulté, Florence Hutcheson

\section{To cite this version:}

Karl-Stéphane Rossignol, Jan Werner Delfs, Michael Mössner, Denis Gély, Jean Bulté, et al.. Experimental Investigations on Noise Shielding: Dependency on Reference Noise Source and Testing Environment. AIAA/CEAS Aeroacoustics Conference, 2018, Jun 2018, ATLANTA, United States. 10.2514/6.2018-2820 . hal-02907100

\section{HAL Id: hal-02907100 \\ https://hal.science/hal-02907100}

Submitted on 27 Jul 2020

HAL is a multi-disciplinary open access archive for the deposit and dissemination of scientific research documents, whether they are published or not. The documents may come from teaching and research institutions in France or abroad, or from public or private research centers.
L'archive ouverte pluridisciplinaire HAL, est destinée au dépôt et à la diffusion de documents scientifiques de niveau recherche, publiés ou non, émanant des établissements d'enseignement et de recherche français ou étrangers, des laboratoires publics ou privés. 


\title{
Experimental Investigations on Noise Shielding: Dependency on Reference Noise Source and Testing Environment
}

\author{
Karl-Stéphane Rossignol ${ }^{1}$, Jan Werner Delfs ${ }^{2}$, Michael Mößner ${ }^{3}$ \\ DLR (German Aerospace Center), Braunschweig, 38108, Germany \\ Denis Gély ${ }^{4}$ and Jean Bulté ${ }^{5}$ \\ ONERA (French Aerospace Center), Châtillon, 92320, France \\ Florence Hutcheson ${ }^{6}$ \\ NASA Langley Research Center, Hampton, VA
}

\begin{abstract}
This paper presents the experimental results of a study conducted at DLR, ONERA and NASA on the shielding of sound by an NACA 0012 airfoil. The work presented was done in the context of the AVT-233 working group of the Science and Technology Organization (STO) of NATO. The experiments were conducted in the DLR Acoustic Wind Tunnel Braunschweig (AWB), the ONERA F2 tunnel and the NASA Quiet Flow Facility (QFF), with the goal of investigating facility-to-facility effects on the collected data. Two impulsive source concepts were used in the course of these experiments, DLR's laser sound source and ONERA's electric discharge source (SPARC). The collected data reveal that the different tunnel environments do not strongly affect the results obtained with either source. The laser sound source is found to deliver consistent results in all three wind tunnels, for the 7, 14 and $28 \mathrm{kHz}$ octave bands at $\mathrm{M}=\mathbf{0 . 0}$ and $\mathrm{M}=\mathbf{0 . 1 6}$. In the highest octave band considered (56 $\mathrm{kHz}$ ), the results are found to be very sensitive to the choice of operating parameters. The SPARC source also delivered consistent results in the low frequency range, in both the $F 2$ tunnel and the AWB, for both Mach numbers tested. This joint effort has led to the development of a highly valuable database for the validation of shielding prediction tools.
\end{abstract}

\begin{tabular}{|c|c|c|}
\hline & & Nomenclature \\
\hline$p_{s}^{\prime r}(t), p_{i}^{\prime r}(t)$ & $=$ & $\begin{array}{l}\text { acoustic pressure of scattered (s), isolated (i) field as measured (or computed), i.e., not corrected } \\
\text { for nose cone effects }\end{array}$ \\
\hline$\hat{p}^{r}(f), \hat{p}(f)$ & $=$ & spectrum (Fourier coefficient) of $p^{\prime r}(t)$ or (nose cone) corrected $p^{\prime}(t)$ \\
\hline $\operatorname{PSD}^{(r)}(f)$ & $=$ & $\begin{array}{l}\text { spectrum (power spectral density based on finite duration time average or ensemble average) of } \\
p^{\prime r}(t) \text {. }\end{array}$ \\
\hline $\operatorname{PSD}(f)$ & $=$ & $\begin{array}{l}\text { spectrum (power spectral density based on finite duration time average or ensemble average) of } \\
\text { (nose cone) corrected pressure } p^{\prime}(t) \text {. }\end{array}$ \\
\hline$\eta(f)$ & $=$ & narrow band spectrum of shielding factor \\
\hline$\gamma_{p}(f)$ & $=$ & narrow band shielding level \\
\hline$\gamma_{p(1 / 1)}^{n}\left(f_{c}\right)$ & $=$ & normalized octave band shielding level ( $f_{c}$ center frequency) \\
\hline$\gamma_{p(\infty)}^{n}$ & $=$ & overall normalized shielding level (shielding of white noise) \\
\hline$\gamma_{p(\infty)}$ & $=$ & overall corrected shielding level (overall shielding of actual laser pulse) \\
\hline$\gamma_{p(\infty)}^{r}$ & $=$ & overall uncorrected shielding level (including nose cone characteristics) \\
\hline$r_{0}$ & $=$ & displacement vector \\
\hline
\end{tabular}

${ }^{1}$ Research Engineer, Institute of Aerodynamics and Flow Technology, AIAA Senior Member

${ }^{2}$ Head of Technical Acoustics Department, Institute of Aerodynamics and Flow Technology, AIAA Senior Member

${ }^{3}$ Research Engineer, Institute of Aerodynamics and Flow Technology, AIAA Senior Member

${ }^{4}$ Director of Aeroacoustics Department, AIAA Senior Member

${ }^{5}$ Research Engineer, Aeroacoustics Department

${ }^{6}$ Research Engineer, Aeroacoustics Branch, AIAA Associate Fellow 


$\begin{array}{ll}r_{0} & =\text { magnitude of the displacement vector } \\ \boldsymbol{x} & =\text { observer position vector } \\ \boldsymbol{\xi}_{\mathbf{0}} & =\text { source position vector }\end{array}$

\section{Introduction}

Toise is not only a problem with civil aviation but in the military sector as well. Jet propelled agile (unmanned) air vehicles generate particularly intense noise during operation. This is a problem in peacetime due to community annoyance during necessary training and test flights, and in wartime because of the risk of an early acoustic detection of the aircraft by the enemy. The particular engine integration of such vehicles is essential for turning them into either noisier or quieter aircrafts. However, today, noise is not part of the design process, but comes as a more or less problematic by-product after the configuration is fixed. The potential of clever engine integration and its corresponding beneficial acoustic installation effects for particularly low noise vehicles is not exploited. The problem here is that, as opposed to more classical design disciplines, noise predictions are not as advanced. The applicability for low noise vehicle design of acoustic prediction methods is sometimes unclear, and the methodologies not often validated.

In order to establish a sound aeroacoustic shielding database for a firsthand validation of acoustic prediction codes, a set of interrelated aeroacoustic shielding tests were planned and executed. The emphasis was put on an extensive 2D diffraction study for a well-known airfoil geometry, namely the NACA 0012. These studies laid the groundwork for which the characterization of acoustic shielding properties of actual aircraft geometries was done. The 2D shielding tests presented herein were conducted in DLR's Acoustic Wind Tunnel Braunschweig (AWB), ONERA's F2 LowSpeed Wind Tunnel and NASA's Quiet Flow Facility (QFF) for nominally the same test conditions in order to learn about the measurement scatter across different facilities. In the AWB and the F2 facilities, two different acoustic sources were implemented and used for these shielding tests, namely DLR's laser source and ONERA's electric discharge source (SPARC). In the QFF facility, a separate laser source was used. A major objective of this study was to determine how consistent the measured data would be across the three facilities, since each has a different test section configuration. The AWB and QFF have, respectively, a fully open and partially open test section, while that of the F2 is closed.

The results reported herein were obtained in the context of the AVT-233 working group of the Science and Technology Organization (STO) of NATO. The purpose of the AVT-233 was to help identify and validate appropriate acoustic prediction methods as a basis for low noise military aircraft design with a focus on acoustic shielding of engine noise.

\section{Reference Noise Sources}

Two acoustic source concepts were developed and employed in the acoustic shielding tests carried out in the framework of AVT 233. The first source, the laser-induced sound source, relies on the focusing of a laser beam by an appropriate lens system onto a point in space where a very short light pulse generates a plasma and thus, an acoustic pressure pulse. This concept is nonintrusive in nature and was developed by DLR. The second source, SPARC, is based on an electric discharge between two electrodes. It was developed by ONERA and is intrusive, but bears the advantage of providing a very strong signal such that good Signal-to-Noise $(\mathrm{S} / \mathrm{N})$ ratios may be achieved.

\section{A. DLR Laser Sound Source}

For the investigation of noise shielding properties of generic bodies or aircraft configurations, it is necessary to utilize a reference sound source with known characteristics (i.e., known directivity and spectral content). Such a source can be realized using a conventional loudspeaker or, as in [1], using customized pipe arrangements and pressurized air. However, the physical dimensions of these sources make their use in aeroacoustic investigations difficult because they interfere directly with the flow field and/or the acoustic field, thus adding perturbation to any acoustic measurement.

A laser-based (nonintrusive) pulsed sound source circumvents all of these inconveniences while providing a reference acoustic pressure wave of nearly uniform directivity and broadband spectral content. Because of its very short pulse duration, the generated sound wave also has the advantage of being easily separated from unwanted 
reflection. Furthermore, its characteristics can be derived directly from the solution of the acoustic wave equations, making its implementation in numerical simulation codes straightforward [2-7].

By focusing a high energy laser beam to a point (i.e., an effective air volume), it is possible to initiate the formation of a small plasma, which rapidly expands [8,9], thus forming a pressure wave about its boundary, which propagates through the surrounding medium. Assuming that the corresponding pressure perturbation, ${ }^{\prime}$, is propagating in a medium of uniform mean density and is moving at a uniform subsonic speed, $p^{\prime}$ can be expressed as

$$
p^{\prime}(\boldsymbol{x}, t)=\frac{(\gamma-1)\left(1-\mathrm{M}^{2}\right)}{4 \pi \mathrm{a}_{\infty}^{2}\left(\sqrt{\left(\boldsymbol{M} \cdot \boldsymbol{r}_{\mathbf{0}}\right)^{2}+\left(1-M^{2}\right) r_{0}^{2}}-\boldsymbol{M} \cdot \boldsymbol{r}_{0}\right)} \frac{\partial \vartheta_{p}}{\partial \tau}
$$

where all variables are to be evaluated at the retarded time $\tau$, which is related to the observer time $t$ by

$$
t=\tau+\frac{1}{a_{\infty}\left(1-M^{2}\right)}\left\{-r_{0} \cdot M+\sqrt{\left(\boldsymbol{r}_{\mathbf{0}} \cdot \boldsymbol{M}\right)^{2}+\left(1-M^{2}\right) r_{0}^{2}}\right\} .
$$

In (1) and (2), the distance $r_{0}(\tau)$ is the magnitude of the vector from source location, $\xi_{\mathbf{0}}(\tau)$, to observer location, $\boldsymbol{x}$, (i.e., $\boldsymbol{r}_{\mathbf{0}}:=\boldsymbol{x}-\boldsymbol{\xi}_{\mathbf{0}}$ ) at emission time $\tau$. $a_{\infty}$ represents the speed of sound, $\gamma$ is the isentropic exponent and $\vartheta_{p}$ is the time history of the actual heat release at the (moving) source position. Equation (1) emphasizes the importance of the temporal heat input $\left(\partial \vartheta_{p} / \partial \tau\right)$ in generating a high amplitude pressure wave. Moreover, such a pressure wave does not exhibit any directionality for a medium at rest but features convective amplification in the direction of convection for a moving medium.

To achieve plasma formation, a minimum amount of laser power or irradiance, $I$ (in $\mathrm{W} / \mathrm{cm}^{2}$ ), has to be provided into the medium to reach the breakdown threshold $\left(I_{t}\right)$ for the initiation of plasma formation. Once $I_{t}$ is reached, the plasma starts building up, and its temperature and density increase greatly while absorbing a large portion of the input laser beam energy [10,11]. A theoretical description of the phenomenon is provided by the multiphoton ionization and cascaded ionization mechanisms [12]. In its early stage, the expanding plasma generates a pearshaped pressure front with initial supersonic propagation speed, which becomes an almost omnidirectional pressure wave in the far field [12,13]. The initial shock wave slows down to the isentropic speed of sound after approximately $20 \mu \mathrm{s}$, at which point it propagates as an isentropic acoustic wave. Consequently, the small plasma generated can be seen as a breathing sphere with $10 \mathrm{~mm}$ radius [6]. The value of $I_{t}$ is of about $3.5 \times 10^{12} \mathrm{~W} / \mathrm{cm}^{2}$ for an irradiation of wavelength $\lambda=532 \mathrm{~nm}$ in air and at standard atmospheric pressure [14]. The breakdown threshold power is dependent on the type of gas, its pressure, the radiation wavelength, the duration of the laser pulse and its focusing conditions [12]. Most relevant for the current practical application, are the last two parameters. Typical time traces and spectra are plotted in Fig. 1.
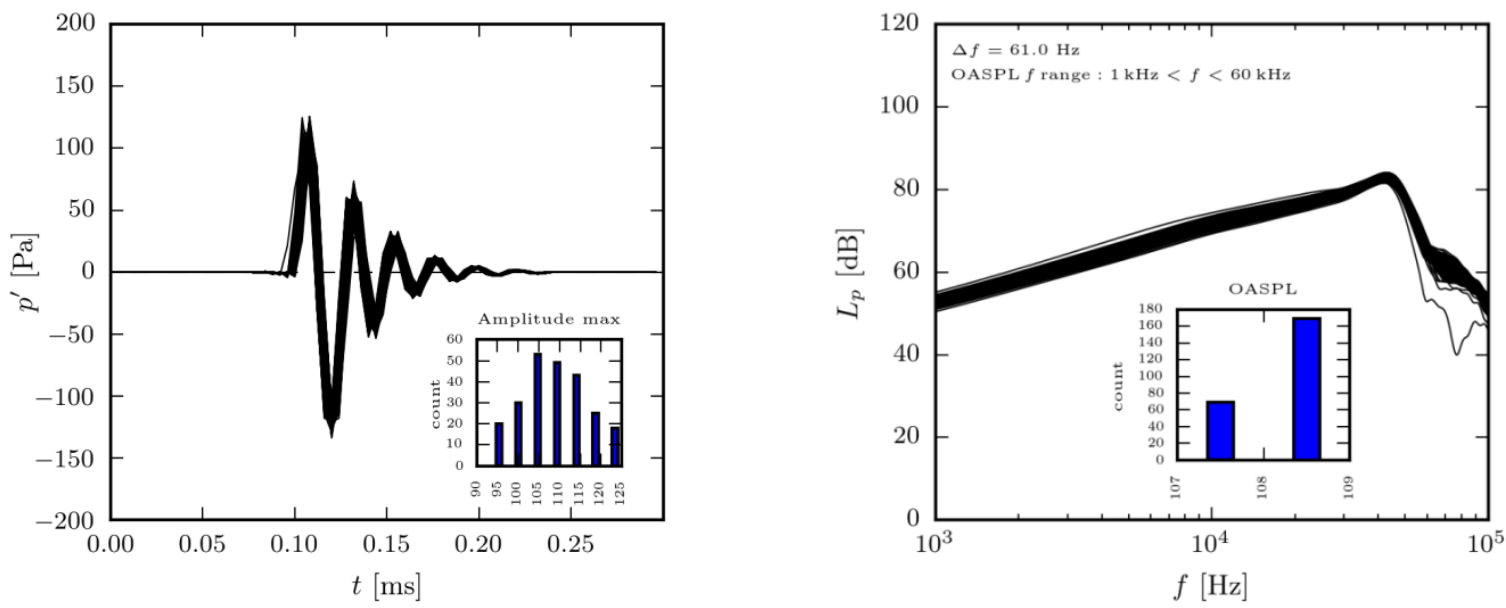

Fig. 1 Characteristic laser-generated pressure waves and spectra. 


\section{B. ONERA SPARC source}

The SPARC source (Source imPulsionnelle AeRoaCoustique) is based on an electrical discharge produced by creating a difference of potential between two electrodes. A strong electric field is created, which ionizes the air between these electrodes. The small ionized air volume between the electrodes conducts a strong electric current that leads to a significant increase of the air volume temperature. This heating is accompanied by a dilation of this volume of air and is immediately followed by a contraction. This phenomenon results in a fluctuation of the local density, which leads to the emission of a high amplitude acoustic N-type wave that propagates uniformly in all directions (Fig. 2).
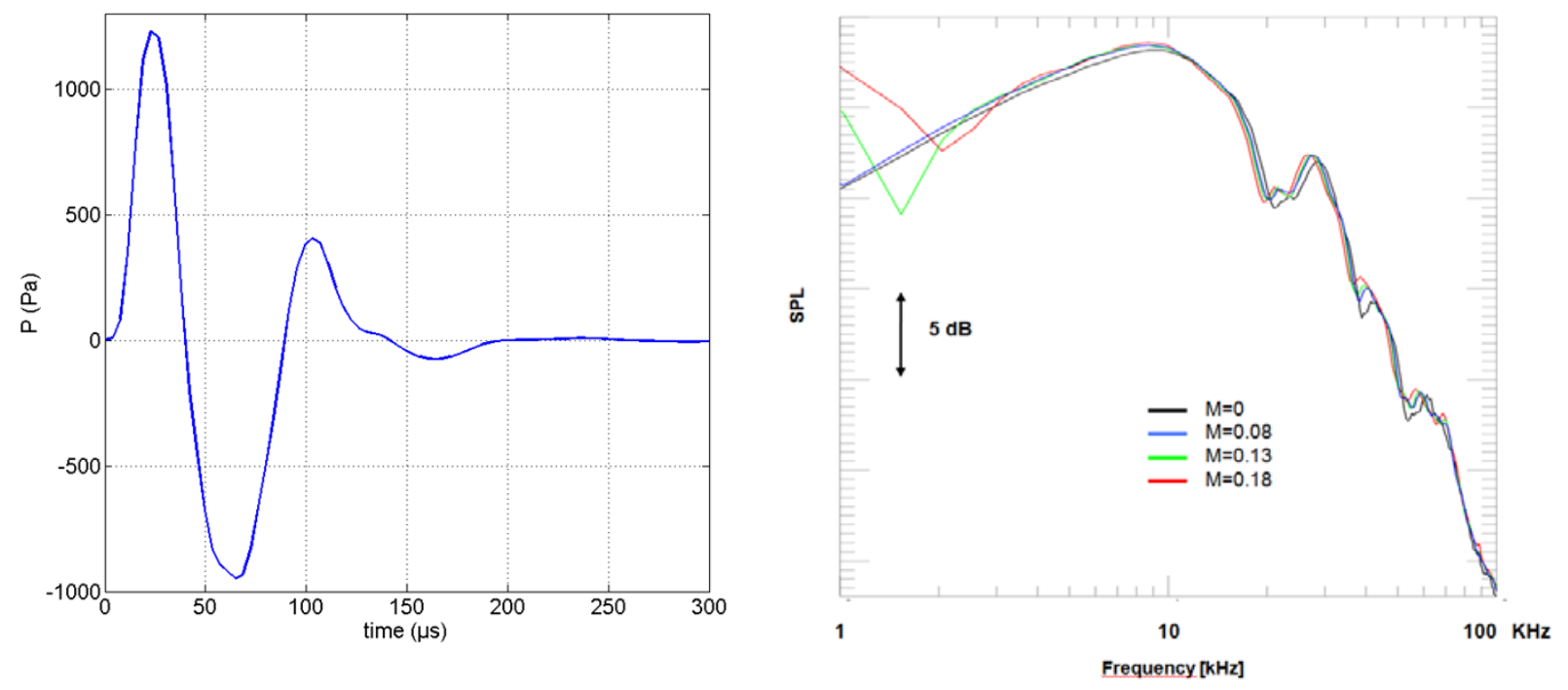

Fig. 2 N-type wave and spectra (1-100 kHz) generated by the SPARC source (basic device).

The isolated pulse signal, which is more than $1000 \mathrm{~Pa}$ in amplitude (peak to peak), is less than $100 \mu$ s in duration. The SPARC source is able to produce electrical discharges at a rate of $10 \mathrm{~Hz}$ for more than 1 minute, resulting in the generation of hundreds of $\mathrm{N}$-waves.

In order to check the performance of the SPARC source in presence of flow, a few tests were carried out in the F2 wind tunnel with a simple flat plate (Fig. 3) before the NACA 0012 profile test campaign.

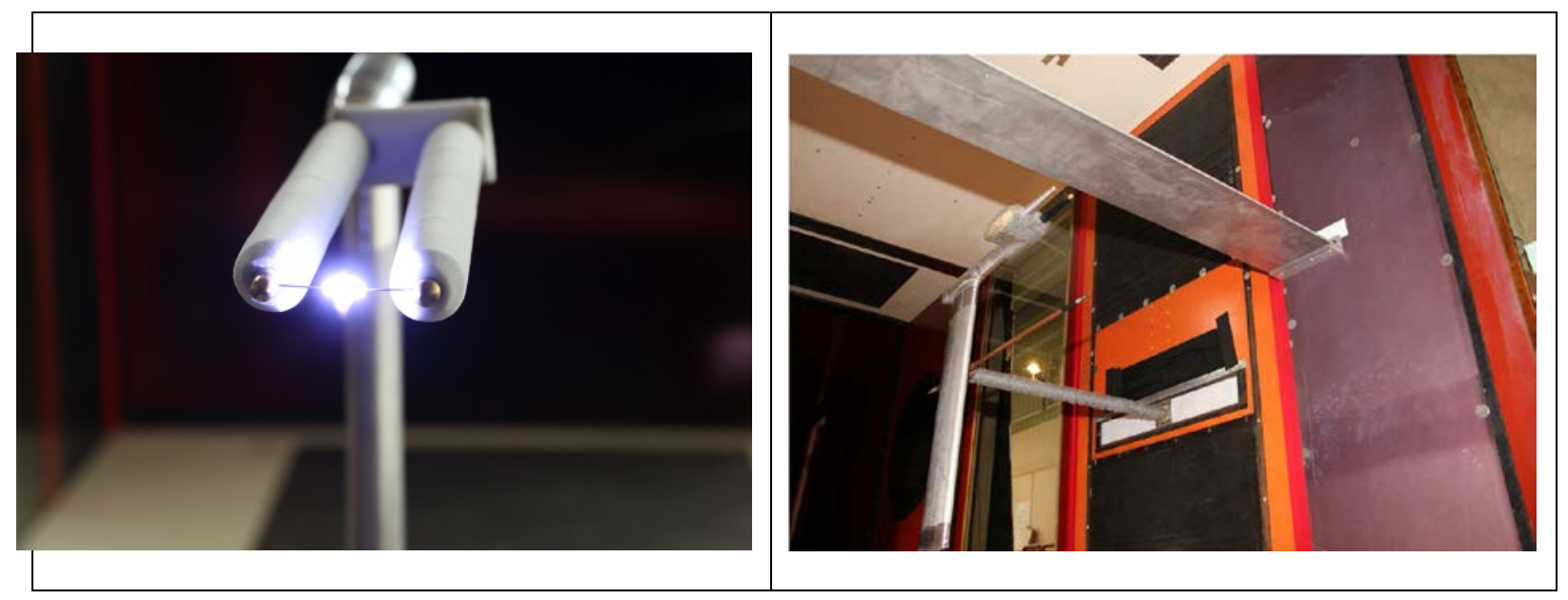

Fig. 3 SPARC source (new design) in F2 for preliminary tests. 
The characteristics of the SPARC source remained consistent in the presence of flow up to $60 \mathrm{~m} / \mathrm{s}$. The reflections on the walls of the wind tunnel were removed using a temporal signal analysis. The acoustic measurements confirmed the expected shielding effect with an increase in SPL on the source-side of the plate due to reflections and a large decrease in SPL on the opposite side, in the shadow zone. The installation effects and consistent output of the SPARC source were verified in these preliminary tests.

\section{Test Facilities}

\section{A. DLR's Acoustic Wind Tunnel Braunschweig (AWB)}

The AWB is DLR's small dimension high-quality anechoic testing facility (see Fig. 4). It is an open-jet Göttingentype wind tunnel capable of running at speeds of up to $65 \mathrm{~m} / \mathrm{s}$, optimized for noise measurements at frequencies above $250 \mathrm{~Hz}$. The test section is $1.2 \mathrm{~m}$ high by $0.8 \mathrm{~m}$ wide. The AWB has been in service since the $1970 \mathrm{~s}$ and is used to conduct research on a wide range of topics, from classical airframe noise problems to propeller/rotor noise, as well as jet installation noise and noise shielding problems. The AWB is equipped with most standard means for the realization of acoustic measurements, as well as basic aerodynamic measurements.

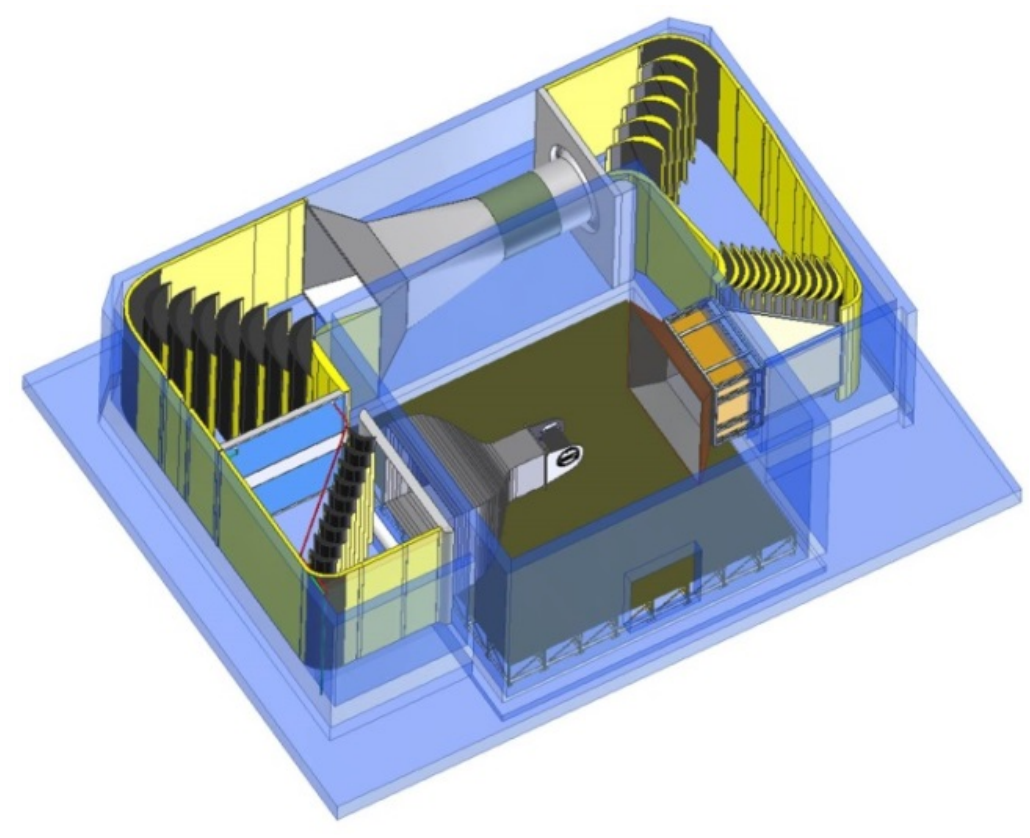

Fig. 4 Acoustic Wind Tunnel Braunschweig (AWB).

\section{B. ONERA's F2 Low-Speed Wind tunnel}

The F2 subsonic wind tunnel (Fig. 5) of ONERA in Fauga-Mauzac, France is a low turbulence, closed test section, research facility with a special focus on laser Doppler anemometry. The test section is $5 \mathrm{~m}$ long by $1.4 \mathrm{~m}$ wide by $1.8 \mathrm{~m}$ high. The side walls of the test section are made up of removable opaque or transparent panels, which allow viewing access to be specially adapted according to the requirements of each test. The wind tunnel is equipped with a 12-bladed fan driven by a $680 \mathrm{~kW}$ direct current motor. The velocity can be continuously varied from 0 to $100 \mathrm{~m} / \mathrm{s}$ by adjusting the motor speed. The total temperature is controlled within $\pm 1^{\circ} \mathrm{C}$ by a water cooler. The settling chamber is equipped with 4 screens, a honeycomb filter, and noise dampers on walls, which, in conjunction with a contraction ratio of 12 , supplies a flow with a very low level of turbulence in the test section (less than $0.05 \%$ ). 

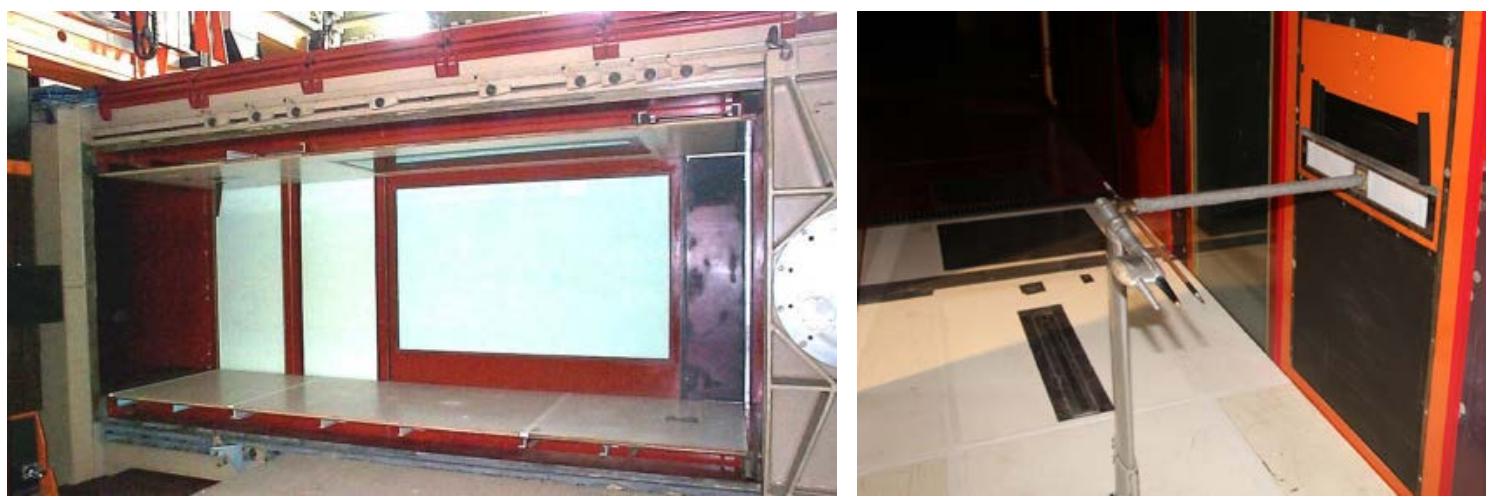

Fig. 5 ONERA Wind tunnel in Fauga-Mauzac (F2).

\section{NASA's Quiet Flow Facility (QFF)}

The QFF is located at the NASA Langley Research Center in Hampton, Virginia. The QFF is specifically designed for aeroacoustic testing. Its anechoic test chamber (Fig. 6) is equipped with a 0.61 by $0.91 \mathrm{~m}$ rectangular partially open wind tunnel nozzle. Two vertical side plates attached to the short sides of the nozzle are used to mount the test models in the test section.

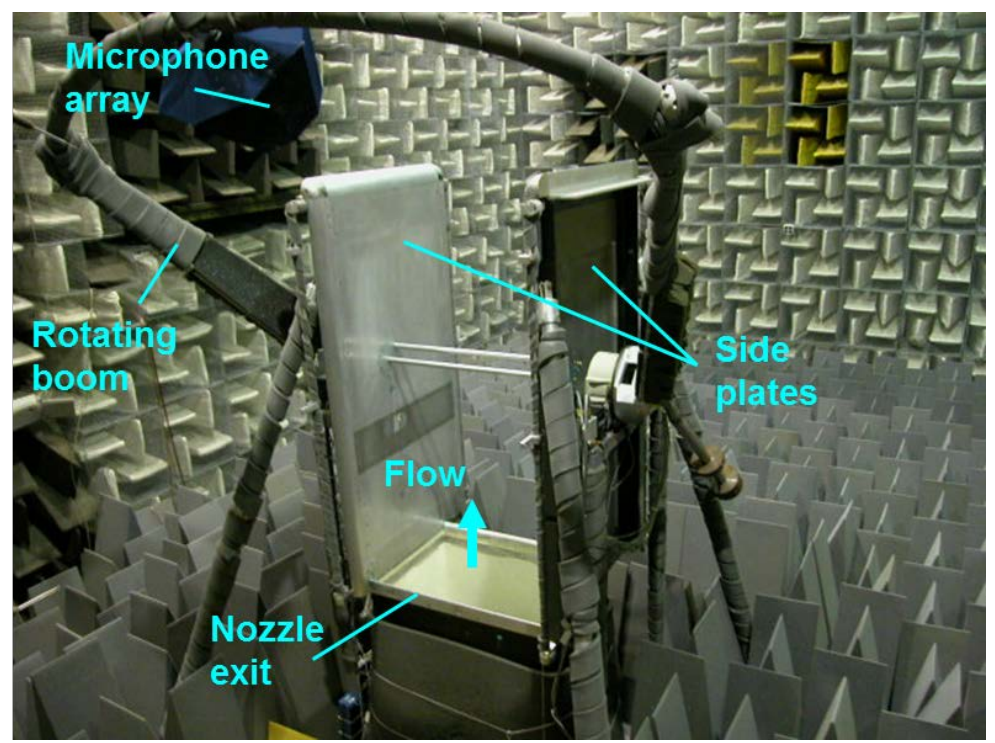

Fig. 6 Quiet Flow Facility test chamber.

The flow circuit employs baffles, turbulence screens and turning vanes to ensure a quiet, low turbulence air flow from the open jet. Flow speeds up to Mach number of 0.17 can be obtained. The anechoic room ( $7.3 \mathrm{~m}$ wide by $9.2 \mathrm{~m}$ long by $6.1 \mathrm{~m}$ high) is lined with wedges, $91.5 \mathrm{~cm}$ deep, to provide an essentially echo-free environment for acoustic measurements down to about $70 \mathrm{~Hz}$. The room is constructed with a $91.5 \mathrm{~cm}$ air space between double walls and is mounted on springs to isolate it structurally from the remainder of the building and thus, minimize the transmission of structure-borne noise arising from other parts of the building. 


\section{Experimental Test Case : NACA 0012 Wing}

\section{A. Experimental Setup in AWB}

A detailed description of the experimental setup is provided in Ref. [2] and is repeated here for completeness. The test setup in the Acoustic Wind Tunnel Braunschweig (AWB) is shown in Fig. 7. The 2D wing with the NACA 0012 profile $(\mathrm{c}=0.2 \mathrm{~m})$ is mounted vertically in the test section with a $0.2 \mathrm{~m}$ offset from the tunnel centerline. This was done to provide enough room for the in-flow microphone to be placed in the geometric far-field of the model. As can be seen in the left part of Fig. 7, the whole laser was tilted $3^{\circ}$ toward the model, to avoid collision of the optical components with the wing's support when moving the source. Measurements were performed for three geometrical angles of attack, $\alpha_{g}=0^{\circ}, \pm 10^{\circ}$, corresponding to effective aerodynamic angles of attack, $\alpha=0^{\circ}, \pm 6^{\circ}$. The correspondence was established through comparison of the experimental pressure distributions to those obtained by CFD. The transition location was determined through stethoscope inspections, and found to occur at $\approx 0.8 \mathrm{c}$ for $\alpha=0^{\circ}$ and $\approx 0.9 \mathrm{c}$ and at $\approx 0.15 \mathrm{c}$ on the pressure and suction sides, respectively, for $\alpha_{g}= \pm 10^{\circ}$. A $0.4 \mathrm{~mm}$ thick straight rectangular trip strip was applied at $\mathrm{x} / \mathrm{c}=0.6$ on the suction side to prevent the occurrence of laminar flow separation.

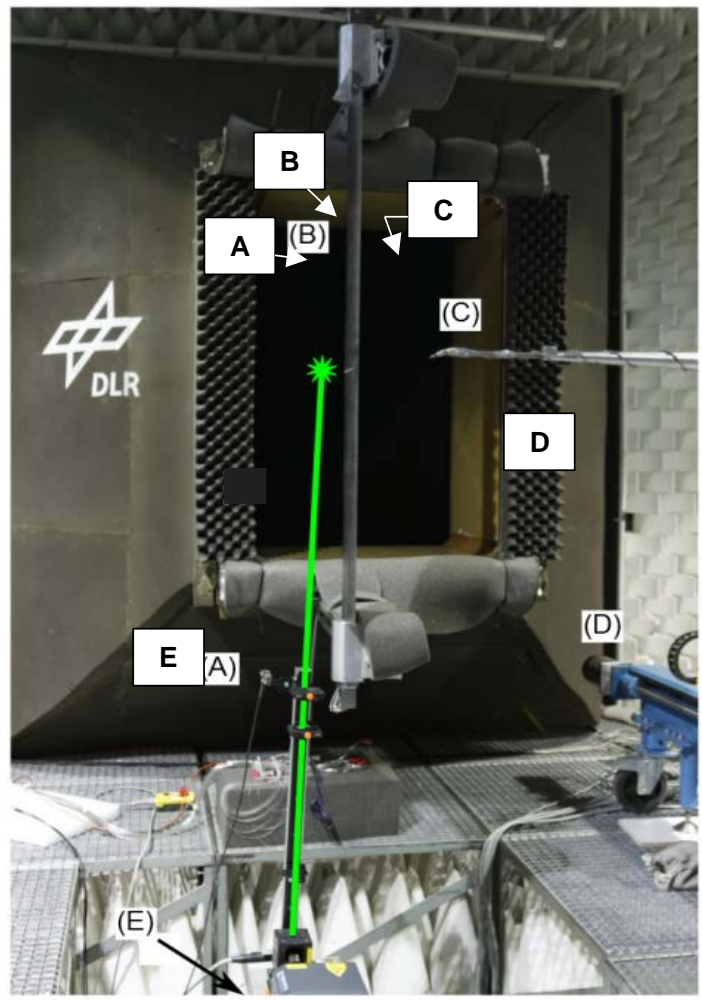

(a) Overview of the complete setup

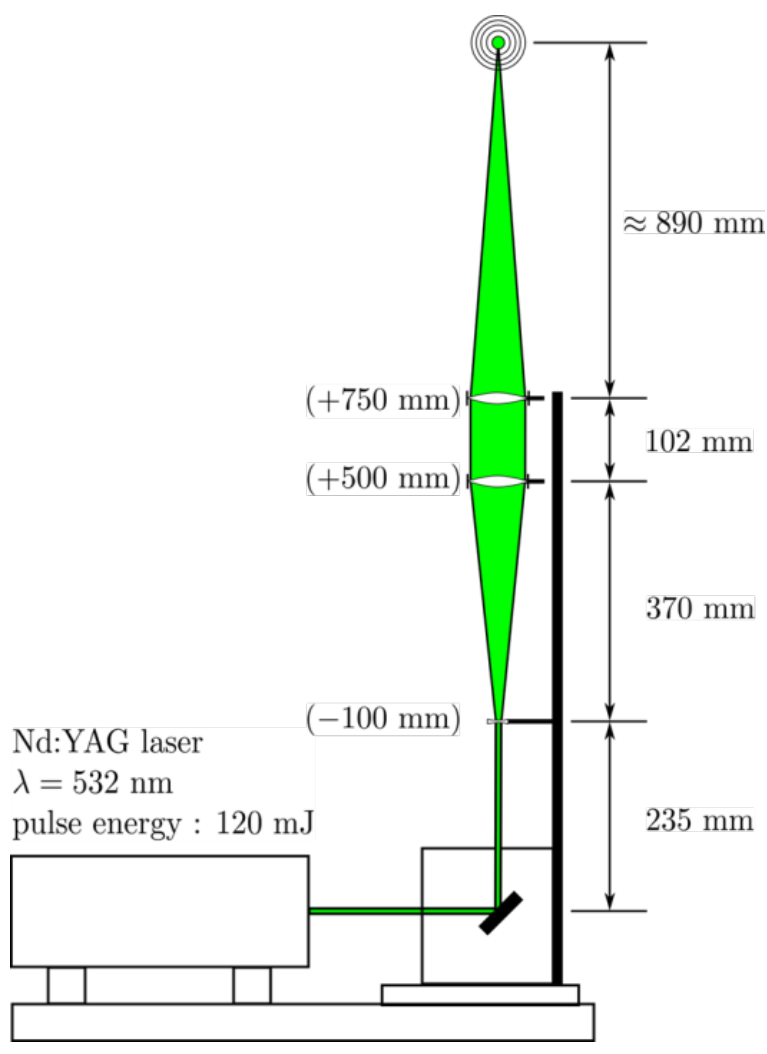

(b) Details of the laser setup

Fig. 7 Experimental setup in AWB. (A) Laser sound source, (B) NACA0012 2D wing, (C) 1/8" GRAS 40DP microphone, (D) microphone positioning system, (E) laser sound source positioning system.

An in-flow microphone was mounted on a linear stage 2 chords $(0.4 \mathrm{~m})$ away from the model chord line, on the opposite side to the sound source (Fig. 7). The in-flow microphone was traversed in streamwise and spanwise directions; however, the focus of the experiment was put on measurements from a streamwise microphone traverse. The sound source was positioned at a constant distance away from the model's surface, on the side of the model opposite to the in-flow microphone. For comparison purposes between DLR, ONERA and NASA, the source was 
located at $\mathrm{x} / \mathrm{c}=0.7$ and $40 \mathrm{~mm}$ from the surface. The evaluation of the shielding efficiency of the model required the acquisition of data once with the model installed and once in the empty test section.

The wind tunnel nozzle was covered with acoustic foam as a preventive measure to ensure that sound wave reflections did not contaminate the measurements, especially in cases where the in-flow microphone was positioned upstream of the wing LE. Preliminary tests revealed, however, that acoustic treatment of the ground, nozzle and positioning elements was not necessary. Reflections generally did not play an important role when using the laser sound source, due to the very short duration of the generated pressure pulses $(\approx 0.1 \mathrm{~ms})$. When a shielding object is present between the sound source and a remote receiver, one has to be more careful to make sure that only the meaningful part of the measured signal is kept for further processing. This is due to the longer propagation paths of the sound waves about the shielding object, requiring longer time series to be inspected in post-processing to capture all of the relevant sound intensity. Details concerning the data acquisition and post-processing procedures can be found in Ref. [2].

\section{B. Experimental Setup in F2}

The ONERA test campaign in the F2 wind tunnel was dedicated to the tests with the SPARC source (ONERA) and with the laser source (DLR). The experimental setup is presented in Fig. 8. The microphone and the SPARC source were moved manually, step by step. The NACA 0012 airfoil with a $200 \mathrm{~mm}$ chord was horizontally mounted in the test section of the wind tunnel. The ceiling and the floor of the test section were $900 \mathrm{~mm}$ from the airfoil. The side walls were located $700 \mathrm{~mm}$ from the midspan. The SPARC source and laser source were alternatively used and placed at the same positions. Pressure taps were used to adjust the angle of attack at 0 degree only. The static condition $(0 \mathrm{~m} / \mathrm{s})$ and a $55 \mathrm{~m} / \mathrm{s}$ flow velocity were tested. The SPARC source pulse rate was $10 \mathrm{~Hz}$, and the acquisition time was 11 seconds in duration. To characterize the diffraction due to the NACA 0012 airfoil, measurements were acquired in the chordwise and spanwise directions. The sampling rate was $262 \mathrm{kHz}$, and the signals were high-pass filtered at $22 \mathrm{~Hz}$.

The realization of DLR's laser-based sound source in the F2 tunnel was done using the same lens and laser setup that was used during the AWB measurement campaign. The complete assembly was mounted on a two-axis displacement system to allow precise positioning of the source about the model surface. Unlike for the AWB, which has an open test section, the F2 tunnel has transparent Plexiglas walls of $20 \mathrm{~mm}$ thickness. Therefore, the laser beam had to go through this wall while being focused near the wing. This, however, was not a problem, and a source of equivalent quality could be produced in both wind tunnels.

As was done in the AWB, acoustic signals were acquired with a GRAS 40DP 1/8" pressure field microphone (provided by DLR) mounted "in-flow" on a traversing arm in the tunnel test section. The microphone position relative to the model was set to exactly replicate the AWB experiment.
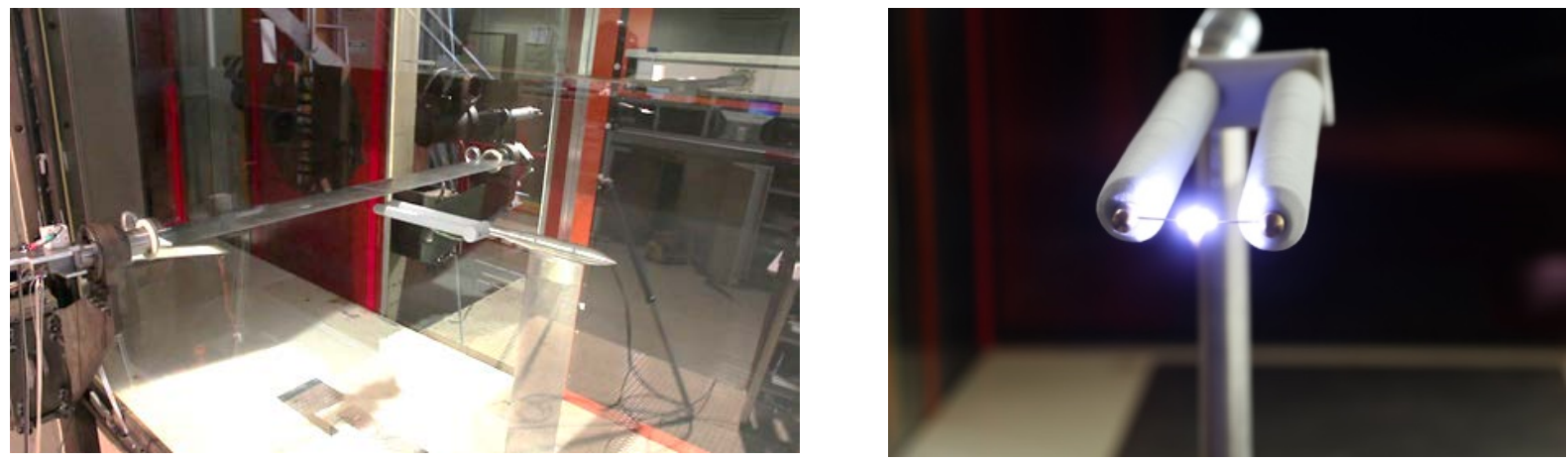

Fig. 8 Experimental setup in F2 wind tunnel. Test section equipped with 2D NACA0012 model and SPARC acoustic pulse source. 


\section{Experimental Setup in QFF}

The experimental setup for the NACA 0012 scattering test conducted in the QFF is shown in Figs. 9 (a) and (b). An NACA 0012 airfoil of $0.91 \mathrm{~m}$ span and $0.2 \mathrm{~m}$ chord was positioned at the center of the test section. It was supported vertically above the nozzle by the two test section side walls. Each end of the airfoil was mounted to a rotating plate to allow for angle of attack changes. A 1/8” $(0.3175 \mathrm{~cm}) 4138$ B\&K microphone equipped with a B\&K UA 0355 nose cone was used to acquire the acoustic measurements inside the test section. It was mounted on a linear traverse attached to the two test section side walls, while the laser and optic assembly was positioned behind one of the test section walls, which was modified to incorporate a $0.95 \mathrm{~cm}$ thick tempered glass window.

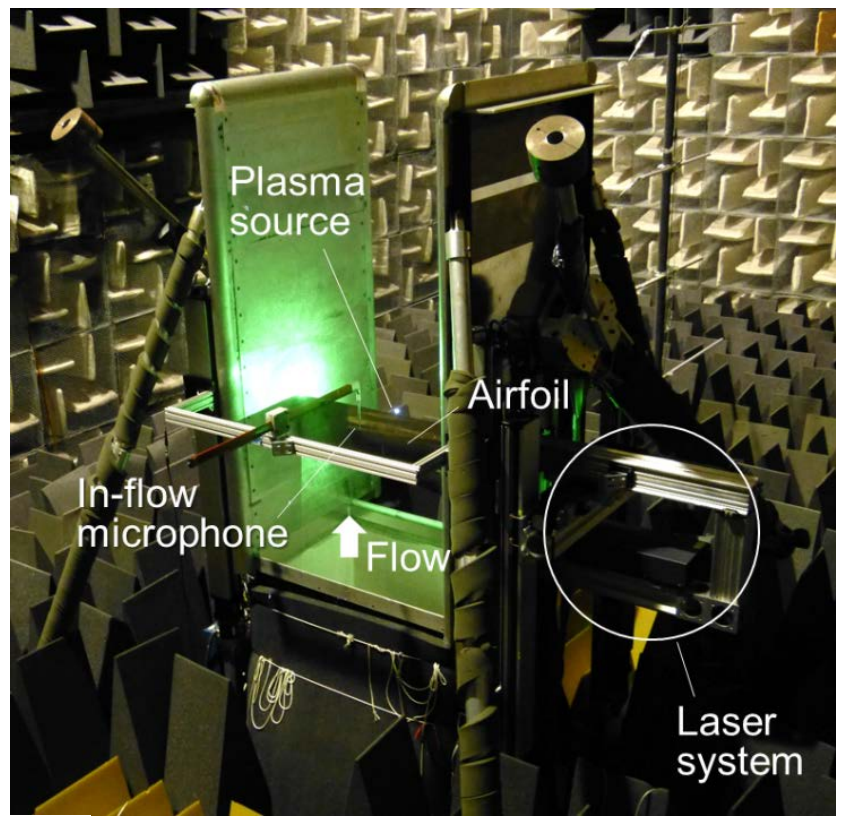

a)

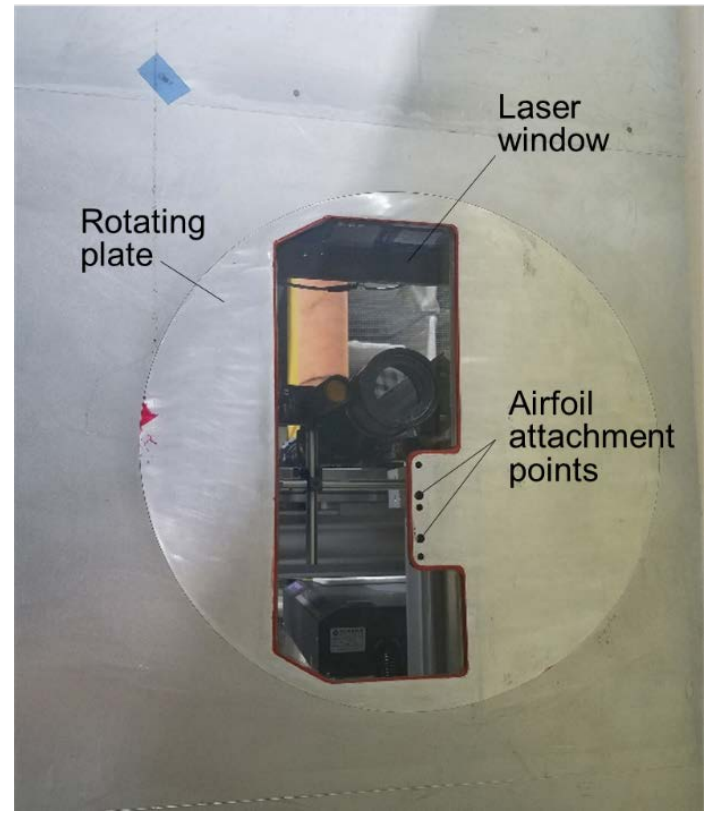

b)

Fig. 9 (a) NASA-QFF experimental set up; (b) Test section wall.

The sound source was generated by a high energy, focusing laser beam. The laser system used was a Nd:YAG, Gemini PIV laser, with an energy pulse of $120 \mathrm{~mJ}$, a wavelength of $532 \mathrm{~nm}$ and a pulse width of 3 to $5 \mathrm{~ns}$. As depicted in Fig. 10, a set of $7.62 \mathrm{~cm}$ diameter achromatic, expansion, collimating and focusing lenses was used to focus the laser beam at the test section midspan to produce a small plasma, which rapidly expands to generate a nearly omnidirectional pressure wave that propagates as an isentropic acoustic wave in the far field. 


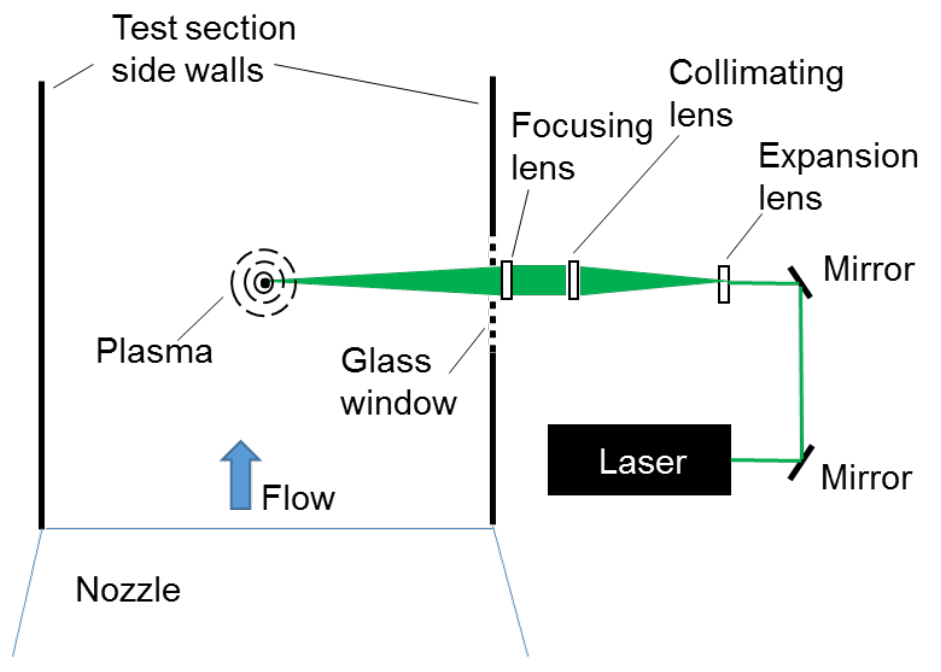

Fig. 10 Sketch of laser and optical lens set-up.

To minimize laser reflections, the path of the laser beam from the laser head to the test section wall window was encased by installing tubes in-between optical lenses, and between the focusing lens and the test section wall window. A photodetector was also positioned near the laser window to record the laser-induced plasma (sound source) occurrences. The traverse system used to position the in-flow microphone and the laser/optic assembly was designed to be compact and rigid in order to minimize flow-induced vibrations. It was used to traverse the in-flow survey microphone in the streamwise direction, and the laser system assembly in both streamwise and crosswise directions to position the sound source at chosen locations.

The laser-induced sound source was generated with a repetition rate of $5 \mathrm{~Hz}$, and the survey microphone response was recorded for $20 \mathrm{~s}$, creating time records of 100 acoustic pulses per data point. The survey microphone data were acquired simultaneously with two different sampling rates, $250 \mathrm{kHz}$ (as in the corresponding DLR and ONERA tests) and $10 \mathrm{MHz}$. (The acoustic datasets acquired at $10 \mathrm{MHz}$ are used for the QFF results presented in this paper.) The low-pass and high-pass filters were set at $100 \mathrm{kHz}$ and $150 \mathrm{~Hz}$, respectively. For the processing of each data point acquired, the time signal was gated to isolate the portion of the signal that corresponds to the sound that is directly propagating from the source or to the scattered sound that is propagating from the leading and trailing edges of the airfoil. The gated time signals were then superposed and averaged. The laser Q-switch (trigger) and photodetector signals (which were also recorded) were used in this process to properly identify the acoustic pulses and superpose the gated signals. Finally, the spectra were calculated using data blocks that were zero-padded to the number of samples needed to obtain a frequency resolution of $61 \mathrm{~Hz}$.

Each set of in-flow (survey) microphone measurements was acquired with and without the airfoil installed (i.e., for shielded and unshielded conditions). These measurements were acquired in the midspan plane of the airfoil, one chord away $(20 \mathrm{~cm})$ from the test section centerline (which is also the airfoil chord line at $0^{\circ}$ angle of attack), as well as two chords away (as in the tests conducted in the AWB and F2 facilities) for a subset of test cases. Microphone measurements performed two chords away from the test section centerline placed the microphone outside of the test section. Measurements at that location were, therefore, only performed without flow. The sound source was positioned at different locations with respect to the airfoil, and microphone surveys were performed for three flow speeds (Mach numbers 0, 0.087 and 0.16) and three angles of attack (AOA), $0^{\circ}$ and $+/-13.1^{\circ}$, corresponding to effective aerodynamic angles of attack, $\alpha^{*}$, of $0^{\circ}$ and $+/-6^{\circ}$, respectively. A detailed description of the QFF shielding test can be found in [15]. 


\section{Results}

\section{A. Definitions of Quantities for Results Presentation}

Before proceeding with a direct comparison of the data, standard quantities are defined for the quantification of the shielding efficiency of the test wing. This will ensure a fair comparison between facilities and between the different reference test sources. The results will be given in terms of "octave-band normalized shielding levels",

$$
\gamma_{p(1 / 1)}^{n}\left(f_{c}\right)=20 \log \left(\eta_{(1 / 1)}^{n}\right)
$$

and in terms of "overall normalized shielding levels"

$$
\gamma_{p}^{n}(\infty)=20 \log \left(\eta_{(\infty)}^{n}\right)
$$

The narrow band spectrum of the shielding factor $\eta(f)$ is defined as,

$$
\eta(f)=\frac{\left|\hat{p}_{s}^{r}\right|}{\left|\hat{p}_{i}^{r}\right|}=\frac{\left|\hat{p}_{s}\right|}{\left|\hat{p}_{i}\right|}=\sqrt{\frac{\mathrm{PSD}_{s}^{r}}{\mathrm{PSD}_{i}^{r}}}=\sqrt{\frac{\mathrm{PSD}_{s}}{\operatorname{PSD}_{i}}}
$$

where $\hat{p}(f)$ are the Fourier coefficients of the Fourier-Transformed pulse. From $\hat{p}(f)$ we determine octave band averages of the shielding factor $\eta_{(1 / 1)}^{n}\left(f_{c}\right)$ (see Eq. 6) for $f_{c}=7 \mathrm{kHz}, 14 \mathrm{kHz}, 28 \mathrm{kHz}, 56 \mathrm{kHz}$, as well as an overall normalized shielding factor $\eta_{(\infty)}^{n}$ (see Eq. 7).

$$
\begin{gathered}
\eta_{(1 / 1)}^{n}\left(f_{c}\right)=\left(\frac{\sqrt{2}}{f_{c}} \int_{f_{c} / \sqrt{2}}^{f_{c} \sqrt{2}} \eta^{2}(f) d f\right)^{1 / 2} \\
\eta_{(\infty)}^{n}=\left(\frac{1}{f_{u}-f_{l}} \int_{f_{l}}^{f_{u}} \eta^{2}(f) d f\right)^{1 / 2}
\end{gathered}
$$

In Eq. 7, $f_{u}=56 \mathrm{kHz} \cdot \sqrt{2}$ and $f_{l}=7 \mathrm{kHz} / \sqrt{2}$. The overall normalized shielding factor is therefore calculated over the frequency range $4950 \mathrm{~Hz}<f<79196 \mathrm{~Hz}$. The motivation behind the use of octave-band average values of the shielding factor is to produce curves that are less oscillatory and therefore more easily interpretable and comparable between experiments. The unconventional choice of octave band central frequencies is motivated by the experimental data and computations available. The frequency-wise determination of the shielding factors ensures that the results will be independent of the source frequency content.

\section{B. Dependency on Testing Environment (facility-to-facility comparisons)}

The facility-to-facility comparison is done based on the averaged octave band shielding levels, $\gamma_{p(1 / 1)}^{n}$. Results for $\mathrm{M}=0$ and $\mathrm{M}=0.16$ are presented in Fig. 11 and Fig. 12, respectively. Results are given for a single source position of $x_{s} / c=0.7$, which is common to all databases.

We first consider results obtained with the laser sound source. The agreement between all datasets is very good at $\mathrm{M}=0$ for $f_{c}=7 \mathrm{kHz}$ and $f_{c}=14 \mathrm{kHz}$ with a data spreading on the order of $\pm 1 \mathrm{~dB}$. Some discrepancies appear in the comparison at $f_{c}=28 \mathrm{kHz}$ and become more significant for $f_{c}=56 \mathrm{kHz}$. For $\mathrm{M}=0.16$, in Fig. 12, a similarly good agreement is observed between all datasets. The important discrepancies observed between datasets for the $f_{c}=$ 
$56 \mathrm{kHz}$ octave band and both $\mathrm{M}=0$ and $\mathrm{M}=0.16$ are related to the nonlinear dependency of the source intensity with the laser power setting and source-receiver separation [2]. This will be discussed in more detail in Section VI.

In Fig. 12, results from both the AWB and F2 tunnels for $\mathrm{M}=0.16$ are plotted. In Figs. 12a and 12d, results for $\mathrm{M}=0$ are also added, along with simulations made for the corresponding cases. In the experiment, the first octave band shielding levels, i.e., $f_{c}=7 \mathrm{kHz}$, are found to lower in magnitude by about $5 \mathrm{~dB}$ over all measurement positions when the tunnel is running, compared to when $\mathrm{M}=0$. This is, for the most part, due to strong low-frequency contamination present in that particular octave band, even after the data are high-pass filtered above $5 \mathrm{kHz}$. This observation is also supported by simulations (shown in Fig. 12a, see companion paper [16]) which display no relevant Mach number dependency of the shielding levels in octave band $f_{c}=7 \mathrm{kHz}$. The simulations were based on the solution of the APE equations using DLR's CAA code PIANO [17], the background flow of which was calculated by solving the RANS equations based on the k-omega turbulence model. The distribution of the narrowband shielding factor in Figs. 16b and 17b again underline that the low frequency measurements suffer from massive noise contamination. Nonetheless, the contamination remains on very similar levels in both AWB and F2, an indication that the results are not strongly dependent on the testing facility. An interesting result, when one considers that AWB and F2 are different types of wind tunnels.

In Fig. 12d, the shielding levels are found to be strongly affected by the presence of the flow field, with an important reduction in shielding effectiveness in the upstream direction of as much as $5 \mathrm{~dB}$. This effect could be explained by sound waves reaching deeper into the shadow region under the combined influence of solid edge diffraction and refraction though boundary layer velocity gradients. It is interesting to note here that this effect is similar in both AWB and F2, thus suggesting that a similar flow field exists around the wing, as is to be expected from the static pressure distributions. In that figure, simulation results are also added to emphasize that the observed effect is flowrelated and not the consequence of contamination in the experimental data. Both simulation curves are shifted up 3 $\mathrm{dB}$ to allow for a better comparison with the experiment. The discrepancies between the AWB and F2 datasets, for $\mathrm{M}=0.16$, and the $3 \mathrm{~dB}$ shift of the simulation results in Fig. 12d, are all related, at least in part, to nonlinear effects (to be discussed further in Section VI).

The agreement found between test facilities in Fig. 11 and Fig. 12 was not, a priori, to be expected, as all three wind tunnel environments greatly differ. The results, however, clearly demonstrate that the laser source, being a very short-duration impulsive source, is not effectively "aware" of its environment. This holds as long as a separation of the source pulse from reflected pulses remains possible in post-processing.

\section{Dependency on Reference Sound Source (source-to-source comparisons)}

In Fig. 13, octave band averaged shielding levels obtained with the SPARC source for the $f_{c}=7 \mathrm{kHz}$ octave band are presented for $\mathrm{M}=0.0$ and $\mathrm{M}=0.16$. The presentation is similar to that of Figs. 11 and 12 . Both at $\mathrm{M}=0.0$ and $\mathrm{M}=0.16$, the results obtained with the SPARC source in AWB and F2 are in good agreement with the results obtained with the laser source (for $f_{c}=7 \mathrm{kHz}$ ). There are no data available at other frequencies. At $\mathrm{M}=0.16$, results obtained with the SPARC source again display no strong dependency on the tunnel environment.

The decreased shielding levels obtained with the laser source in the $7 \mathrm{kHz}$ octave band (Fig. 13b) are again believed to be associated with flow-induced noise contamination. The results obtained with the SPARC source in that same frequency range are believed to be more reliable because of the intrinsic stiffness (and hence low level of flowinduced vibration) of the SPARC source setup. Moreover, the SPARC source generates much higher amplitude pressure pulses and thus a larger signal-to-noise ratio.

\section{Laser Sound Source: Dataset-to-Dataset Differences in the Calculated Shielding Levels}

The discrepancies observed in Fig. 11d and Fig. 12d are discussed in terms of the overall shielding levels for the AWB/F2/QFF datasets. To rule out any issues related to the post-processing procedures used at DLR and NASA, the overall shielding levels calculated using QFF data and processed by both institutions are plotted in Fig. 14a. The solid triangle symbol corresponds to NASA's post-processing while the empty square symbol stands for DLR's 
post-processing. The agreement is excellent and the general offset between QFF vs. AWB and F2 data can now be removed by only considering the first three octave bands in the calculation of the overall shielding level (see Fig. 14b).

It was previously stated that the discrepancies observed in Fig. 11d for $f_{c}=56 \mathrm{kHz}$ are related to the nonlinear dependency at high frequencies of the source intensity with the laser power settings and source-receiver separation [2]. This becomes clear when looking at the spectra of the incident and shielded pressures, $\hat{p}_{i}$ and $\hat{p}_{s}$, and of the corresponding shielding factor $\eta$, for source position $x_{s} / c=0.7$ and microphone position $x / c=0.5$ in Fig. 16 . Thus, in Fig. 16a, data from the QFF are compared to data acquired in AWB, while in Fig. 17b, a comparison between AWB and F2 data is made. In both figures, the shielding factor computed from simulations is also plotted. Looking at the spectrum of $\eta$ in Fig. 16a, one observes that both the QFF and AWB data display a broad hump near $90 \mathrm{kHz}$. The spectrum of $\eta$ calculated with the QFF data also displays, however, a second hump around $50 \mathrm{kHz}$ that is not present in the DLR data. This explains the differences in shielding levels observed in Fig. 11d between the QFF and AWB data for $f_{c}=56 \mathrm{kHz}$. Looking at the comparison between AWB and F2 results in Fig. 17b, one sees that $\eta$ follows very similar curves for both datasets, which is consistent with the good agreement shown in Fig. 16a between the AWB and F2 data.

The simulation results displayed in Figs. 16a, 16b and 17b do not show the high frequency humps of the experimental data. In Figs. 12 and 13 of Ref. 2 (repeated here in Fig. 15 for convenience), it was shown that the general shape of the spectrum of the laser sound source is a nonlinear function of the source-receiver distance and incident laser energy. The simulations (which are based on the linear APE equations) do not take these nonlinear propagations effects into account, but solely an inverse distance linear decay of the sound amplitude with distance to the observer. In the experiment, the unshielded incident pressure is measured some 2 chord lengths away from the source, while the shielded pressure wave originates from diffraction of the original source wave by the wing. Thus, the shielded pressure wave propagates linearly to the microphone from the diffraction point. The reference incident pressure is therefore comparatively too low by approximately $2.5 \mathrm{~dB}$ in the $56 \mathrm{kHz}$ octave band. This leads to biased shielding levels with a higher magnitude in that particular octave band. The better way of determining the reference, unshielded, pressure $\hat{p}_{i}$ would, therefore, be to measure it at a distance to the source comparable to that of the diffracting edges from the source origin. This is something that will be considered in future experiments.

There are also important variations in the overall shape of the spectra between all three experiments. In F2, the glass walls on the optical path of the laser might have an impact on the source characteristics while different laser energy output settings and lens setups in all three wind tunnels might alter the source spectra. For $M=0.16$ (see Fig. 17b), the hump in the spectrum of $\eta$ has almost double in level compared to the when $\mathrm{M}=0$, showing a clear dependency of the spectra on flow velocity. It is to be noted that this increase in eta, due to the presence of the flow, is equally observed in the simulation data for frequencies over $30 \mathrm{kHz}$, again pointing to the mentioned refraction effects in the boundary layer. These aspects would require further investigations for clarification. Without a better understanding of these effects, comparisons between experiments of the shielding effectiveness in the $f_{c}=56 \mathrm{kHz}$ octave band will remain difficult.

\section{Conclusion}

A report on experimental investigations on noise shielding by a generic NACA 0012 airfoil is presented. The dependency of the results on the choice of a specific testing environment and sound source is investigated. Three different wind tunnels are considered, (1) DLR Acoustic Wind Tunnel Braunschweig (AWB), as an anechoic fully open test section facility, (2) NASA Quiet Flow Facility (QFF), as an anechoic partly open test section facility and (3) ONERA F2 tunnel, as a non-anechoic closed section facility. All three facilities are low-speed wind tunnels. Two impulsive sound sources are considered: the nonintrusive laser sound concept of DLR, and the intrusive electric discharge source (SPARC) concept of ONERA.

The results revealed no strong dependency on the choice of wind tunnel environment at $M=0.0$ and $M=0.16$. Results obtained with the laser sound source were found to be prone to some level of flow induced contaminations (from vibrations) at the lowest frequency considered, for $M=0.16$. No important contamination was observed for lower Mach number flows. This difficulty was not directly related to the source, but mostly to the stiffness of the experimental setup. Results obtained from campaigns at DLR and NASA using this source methodology and for $\mathrm{M}=0.0$, are in excellent agreement over the frequency range considered. At $\mathrm{M}=0.16$, results from the AWB 
campaign using the laser sound source compare very well with numerical simulation results done by DLR. At the highest frequency considered herein, results obtained with the laser sound source were found to be very sensitive to the choice of operating parameters. The electric discharge source performed well at the lowest frequency considered in this study.

The analysis presented in this paper provides insights into the uncertainties and variability of the experimental quantification of the shielding efficiency by a generic airfoil. The knowledge gained through this analysis will allow for the identification of the most important sources of error and their mitigation in future experiments. This step is crucial with regard to establishing benchmark databases for the validation of numerical simulation codes.

\section{Acknowledgments}

The work reported herein was done as part of the AVT-233 working group of the Science and Technology Organization (STO) of NATO. The authors would like to thank the group for highly valuable technical discussions.

\section{References}

[1] Hutcheson, F. V., Brooks, T. F., Burley, C. L., Bahr, C. J., and Pope, D. S., "Shielding of Turbomachinery Broadband Noise from a Hybrid Wing Body Aircraft Configuration,” (AIAA 2014-2624), 20th AIAA/CEAS Aeroacoustics Conference, 2014.

[2] Rossignol, Karl-Stéphane and Delfs, Jan Werner (2016): "Analysis of the Noise Shielding Characteristics of a NACA0012 2D Wing” (AIAA 2016-2795), 22nd AIAA/CEAS Aeroacoustics Conference, DOI 10.2514/6.2016-2795.

[3] Rossignol, Karl-Stéphane; Delfs, Jan Werner; Boden, Fritz: “On the Relevance of Convection Effects for a LaserGenerated Sound Source” (AIAA 2015-3146), 21st AIAA/CEAS Aeroacoustics Conference, 2015, DOI 10.2514/6.20153146.

[4] Rossignol, Karl-Stéphane; Lummer, Markus; Delfs, Jan Werner: "Validation of DLR's Sound Shielding Prediction Tool Using a Novel Sound Source” (AIAA 2009-3329), 15th AIAA/CEAS Aeroacoustics Conference, 2009, DOI 10.2514/6.2009-3329.

[5] Rossignol, Karl-Stéphane; Pott-Pollenske, Michael; Delfs, Jan Werner; Silbermann, Jakob; Pereira Gomes, Jorge M.: "Investigating Noise Shielding by Unconventional Aircraft Configurations” (AIAA 2017-3195), 23rd AIAA/CEAS Aeroacoustics Conference, 2017, DOI 10.2514/6.2017-3195.

[6] Boden, Fritz; Delfs, Jan Werner: “Development of a laser-based sound source” (2006), -Inter-Noise, $35^{\text {th }}$ International Congress and Exposition on Noise Control Engineering.

[7] Boden, Fritz: ” Grundlagenuntersuchungen zu einer neuartigen Laserschallquelle“ (2007), DLR, Braunschweig, Institut für Aerodynamik und Strömungstechnik, IB 124-2007/5.

[8] Hosoya, Naoki; Nagata, Masaki; Kajiwara, Itsuro: "Acoustic testing in a very small space based on a point sound source generated by laser-induced breakdown: Stabilization of plasma formation” (2013), Journal of Sound and Vibration, Vol. 332, no. 19, pp. 4572-4583.

[9] Radziemski, L.J.; Cremers, D.A.: “Laser induced plasmas and applications” (1989), Marcel Dekker Inc., ISBN-13: 9780824780784.

[10] Phuoc, Tran X; White, Curt M.: "Experimental studies of the absorption and emissions from laser-induced spark in combustible gases” (2010), Optics communications, Vol. 181, no. 4, pp. 353-359.

[11] Chen, Y-L; Lewis, JWL; Parigger, C.: "Spatial and temporal profiles of pulsed laser-induced air plasma emissions" (2000), Journal of quantitative spectroscopy and radiative transfer, Vol. 67, no. 2, pp. 91-103.

[12] Ostrovskaya, G.V.; Zauidel, A.N.: "Laser spark in gases“ (1974), Physics-Uspekhi, Vol. 16, no.6, pp. 834-855.

[13] Villagrán-Muniz, Mayo; Sobral, Hugo; Navarro-Gonzàlez, Rafael: "Shock and thermal wave study of laser-induced plasmas in air by the probe beam deflection technique” (2003), Measurement Science and Technology, Vol. 14, no. 5, pp. 614-618.

[14] Phuoc, Tran X.: "Laser spark ignition: experimental determination of laser-induced breakdown thresholds of combustion gases” (2000), Optics Communications, Vol. 175, no. 4, pp. 419-423.

[15] Hutcheson, F. V., Bahr, C. J., Thomas, R. H., and Stead, D. J., "Experimental Study of Noise Shielding by a NACA 0012 Airfoil,” AIAA AVIATION 2018, 24th AIAA/CEAS Aeroacoustics Conference 2018, Atlanta, GA

[16] Lummer, M.; Mößner, M.; Delfs, J.W., "Computation and Validiation of Acoustic Shielding at Realistic Aircraft Configurations”, AIAA AVIATION 2018, 24th AIAA/CEAS Aeroacoustics Conference 2018, Atlanta, GA.

[17] Delfs, J.W.; Bauer, M.; Ewert, R.; Grogger, H.A.; Lummer, M.; Lauke, T.G.W., "Numerical Simulation of Aerodynamic Noise with DLRs aeroacoustic code PIANO”, User Manual. 2008. Available online: http://elib.dlr.de/118928/1/Piano_handbook_5.2_open.pdf (accessed on 14 December 2017). 


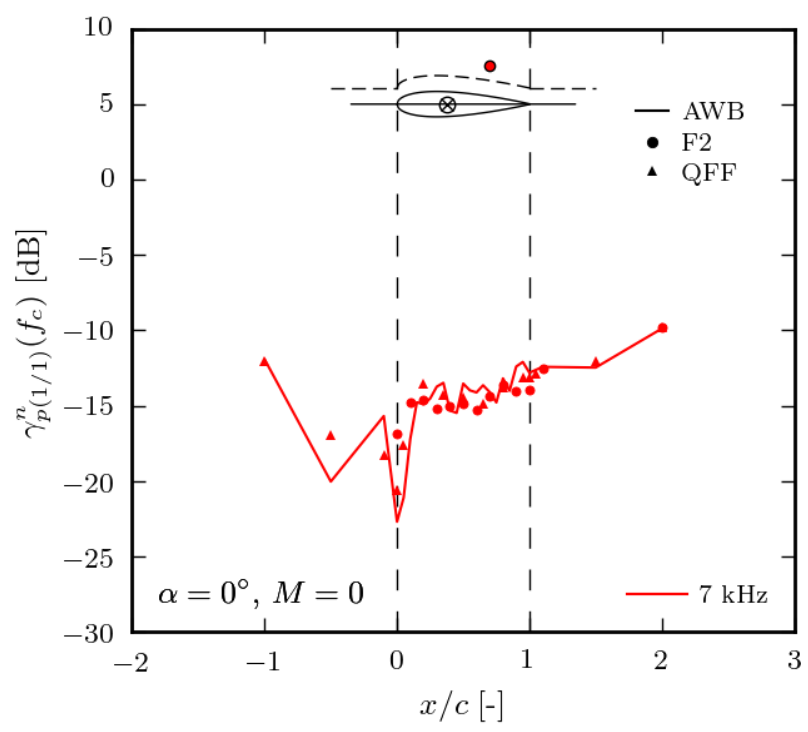

(a) $7 \mathrm{kHz}$

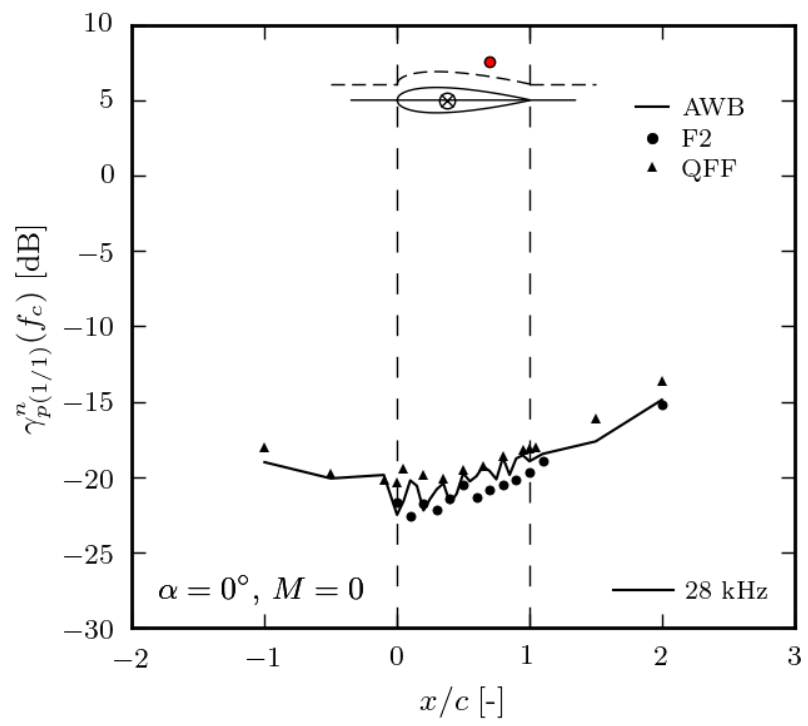

(c) $28 \mathrm{kHz}$

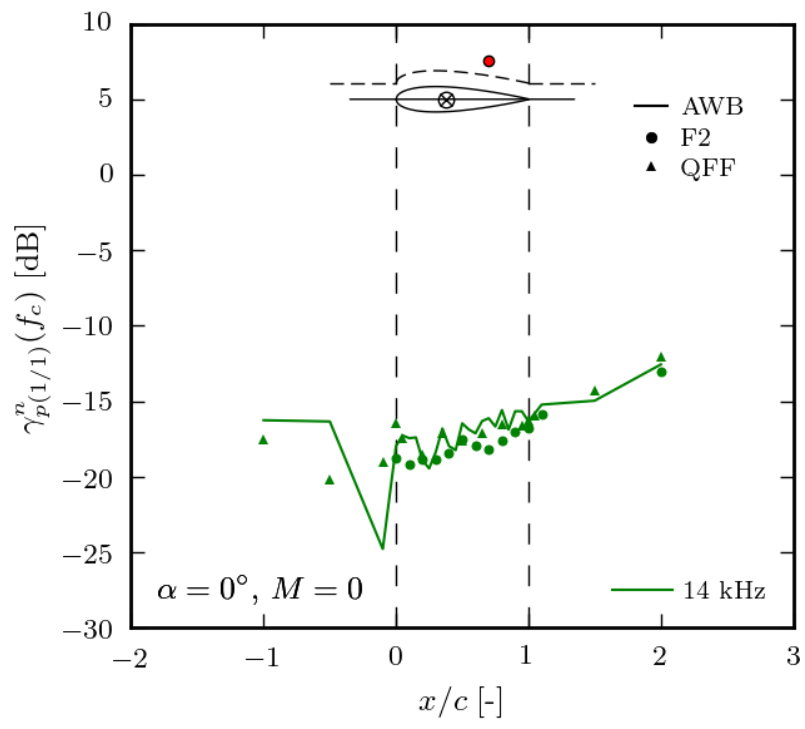

(b) $14 \mathrm{kHz}$

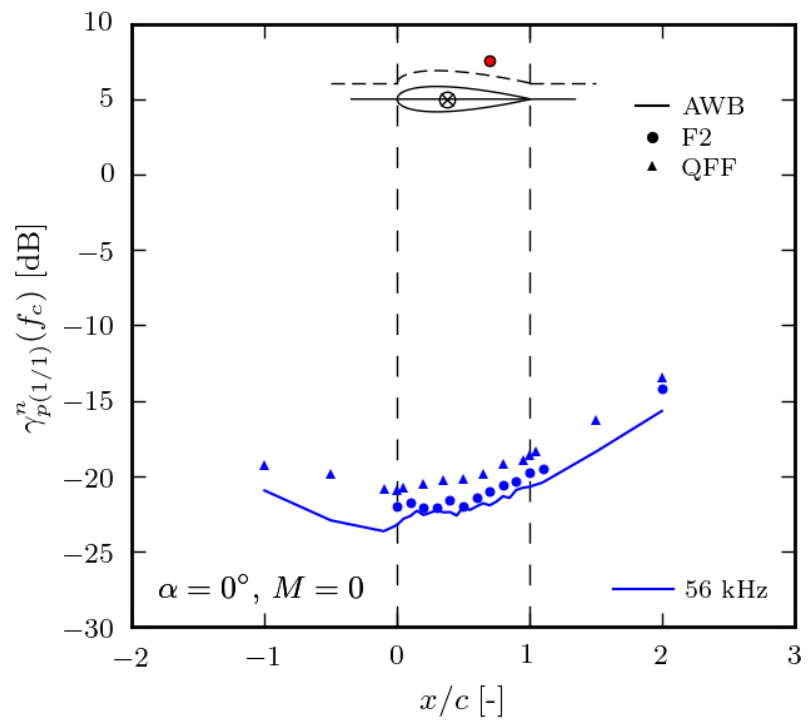

(d) $56 \mathrm{kHz}$

Fig. 11 Comparison of octave-band averaged shielding levels; laser sound source in AWB vs F2 vs QFF, M=0. 


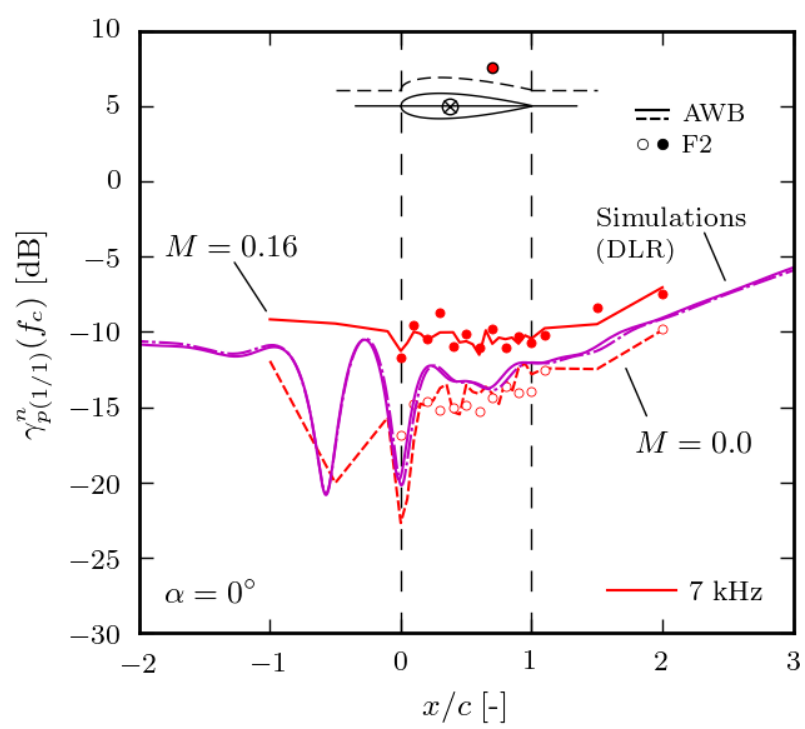

(a) $7 \mathrm{kHz}$

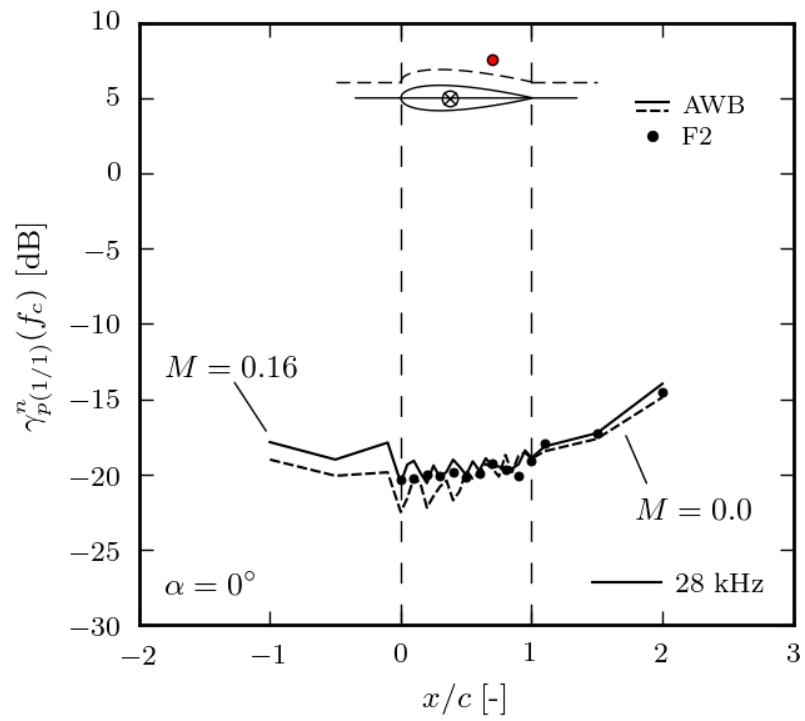

(c) $28 \mathrm{kHz}$

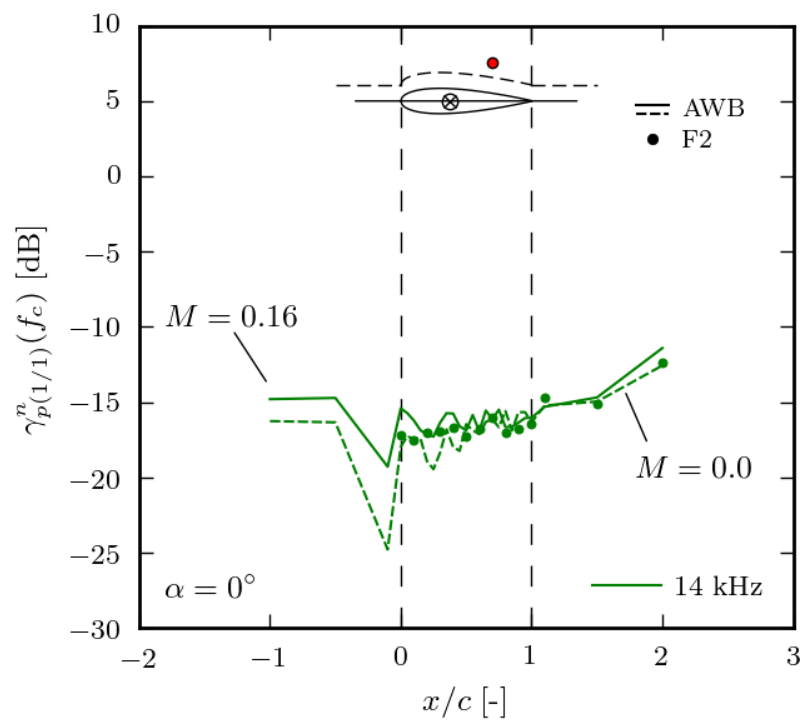

(b) $14 \mathrm{kHz}$

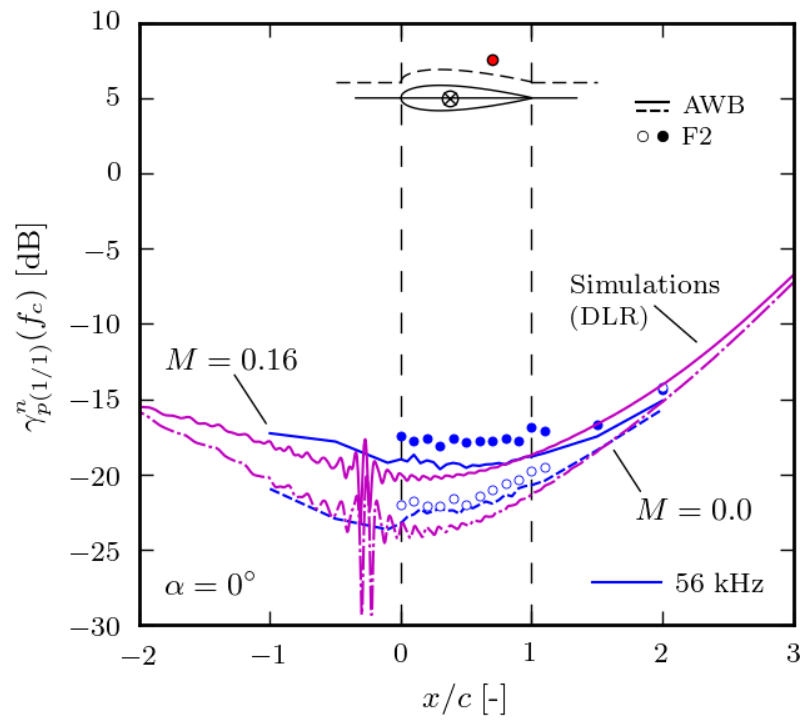

(d) $56 \mathrm{kHz}$

Fig. 12 Comparison of octave-band averaged shielding levels; laser sound source in AWB vs F2, M=0.16. In (d), simulated shielding levels shifted up by $3 \mathrm{~dB}$ (approximate contribution of nonlinearities in the $56 \mathrm{kHz}$ octave band experimental results). 


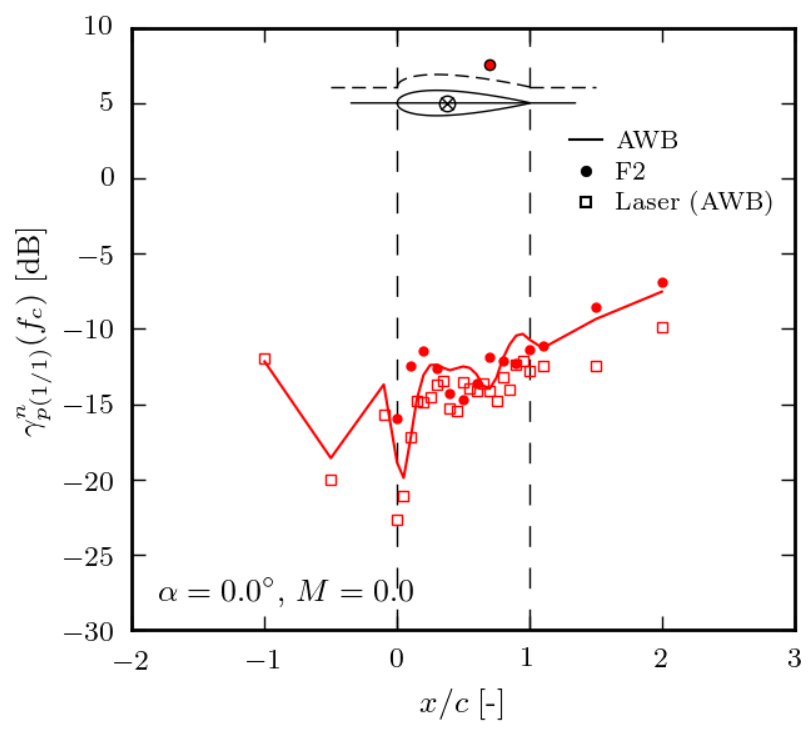

(a) $\mathrm{M}=0.0$

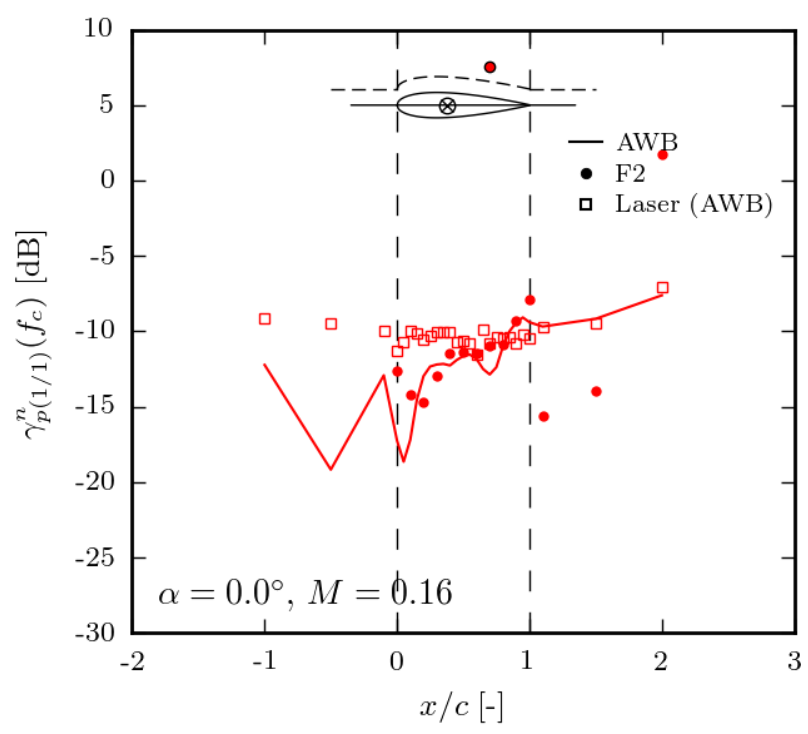

(b) $\mathrm{M}=0.16$

Fig. 13 Comparison of octave-band averaged shielding levels; $f_{c}=7 \mathrm{kHz}$; SPARC sound source in AWB vs F2. Results for the laser sound source ( $\square$ ) in AWB are added for comparison.

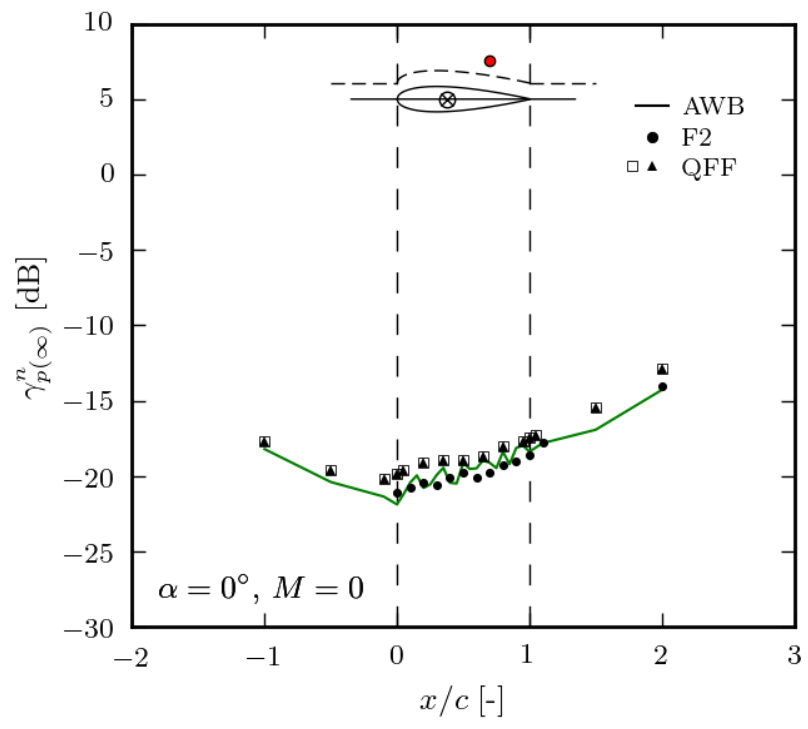

(a) $5.0-79.2 \mathrm{kHz}$

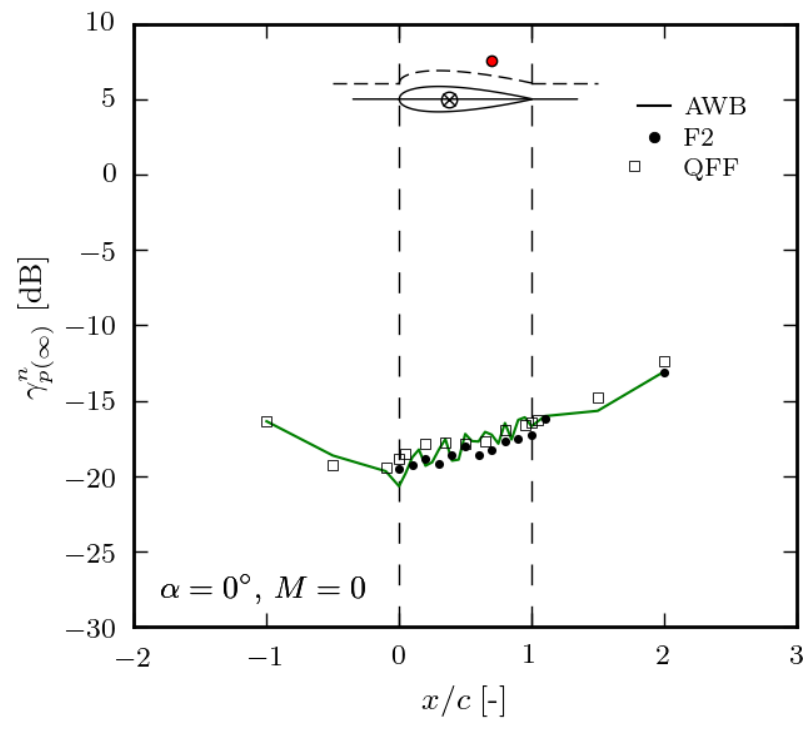

(b) $5.0-40.0 \mathrm{kHz}$

Fig. 14 Overall shielding level, $M=0$, (a) post-processing algorithm comparison and discrepancies between datasets, $\square$ : DLR post-processing of QFF data, $\triangle$ : NASA post-processing of QFF data (b) only the first three octave bands are considered. 


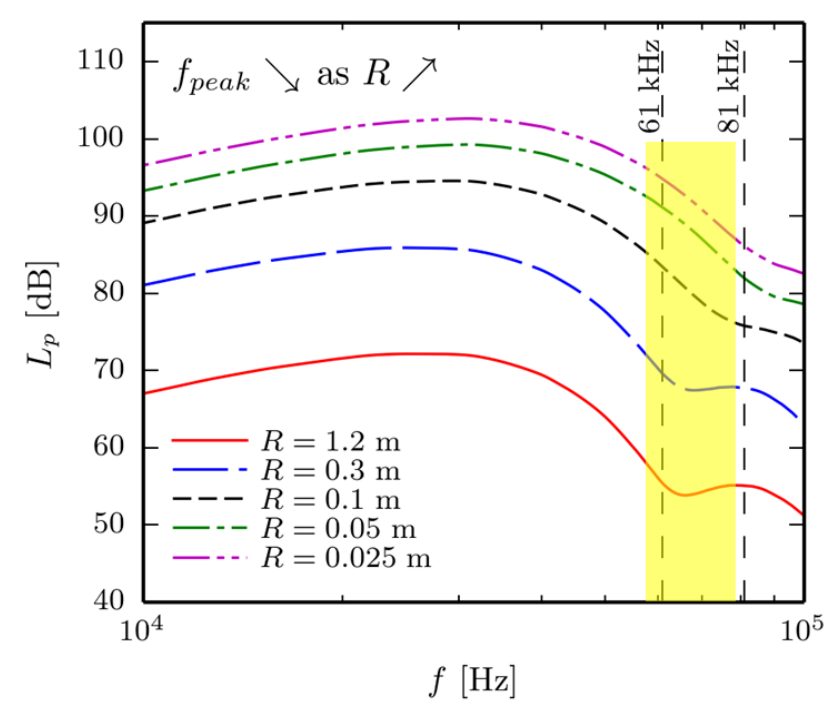

(a) Sound pressure level spectrum vs. $\mathrm{R}$

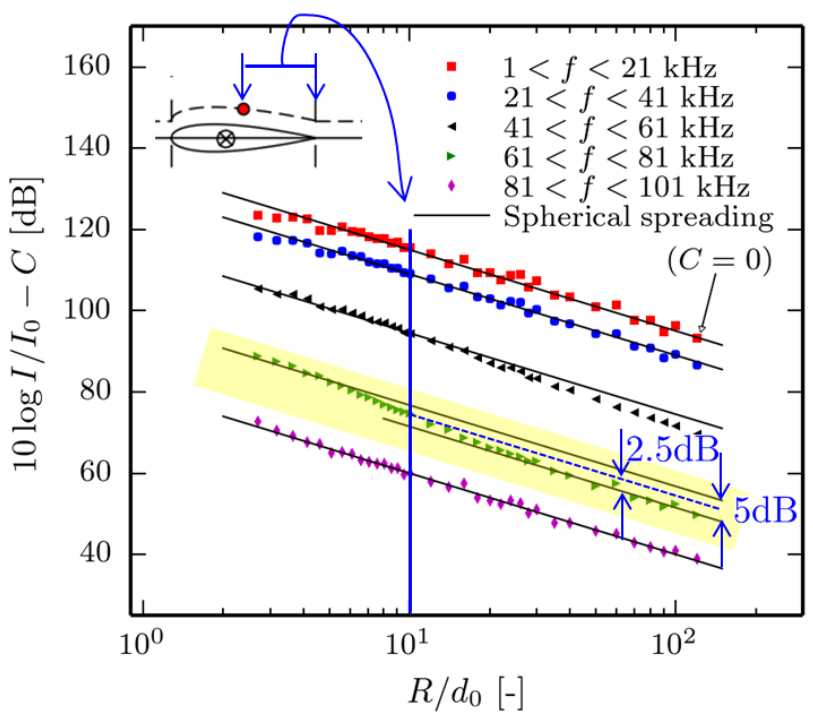

(b) Bandwise integrated sound intensity vs. $\mathrm{R}$

Fig. 15 Spectral shape vs. source-receiver distance (R). $M=0, \theta_{i}=0^{\circ}$.

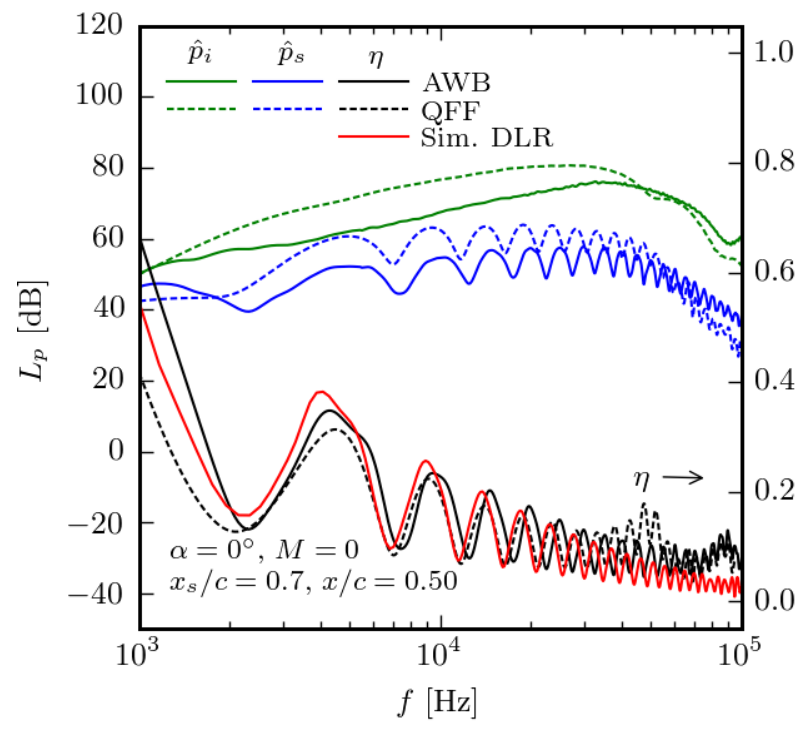

(b) Laser source in AWB vs. QFF, M=0.0

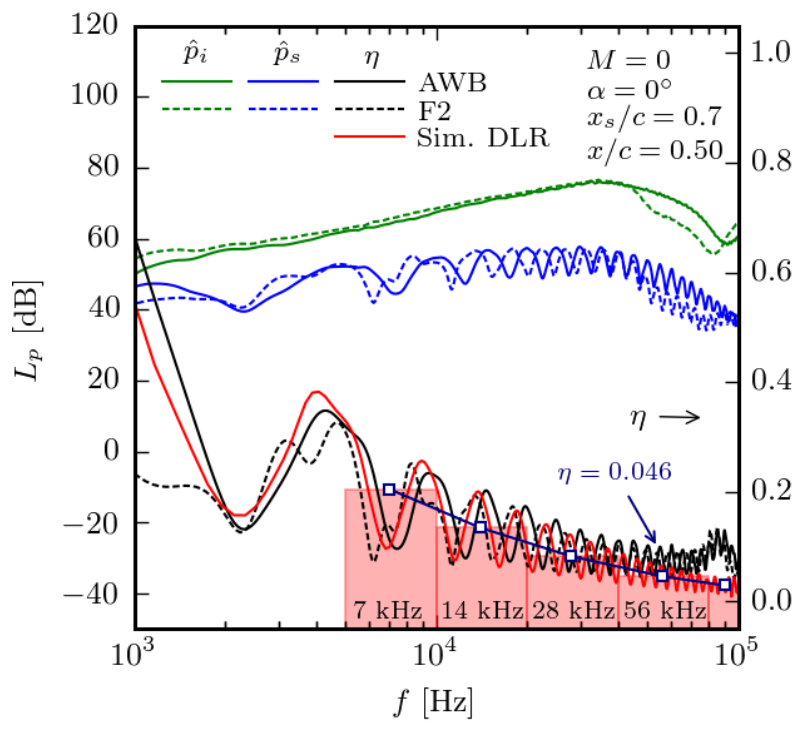

(b) Laser source in AWB vs. F2, M=0.0

Fig. 16 Spectra of the incident, $\widehat{p}_{\mathbf{i}}$, and shielded, $\widehat{p}_{s}$, pressures and of the shielding factor $\eta$, source position $x_{s} / c=0.7$, microphone position $x / c=0.5, \alpha=0^{\circ}, M=0$. Octave bands and respective average value of $\eta$ shown by shaded area and empty square symbols in (b). 


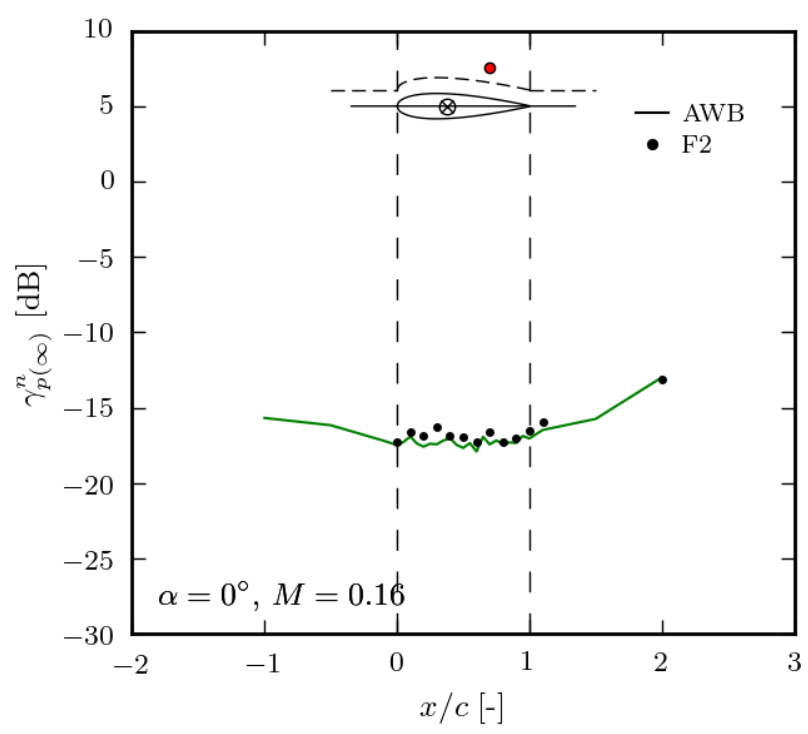

(a) $5.0-79.2 \mathrm{kHz}$

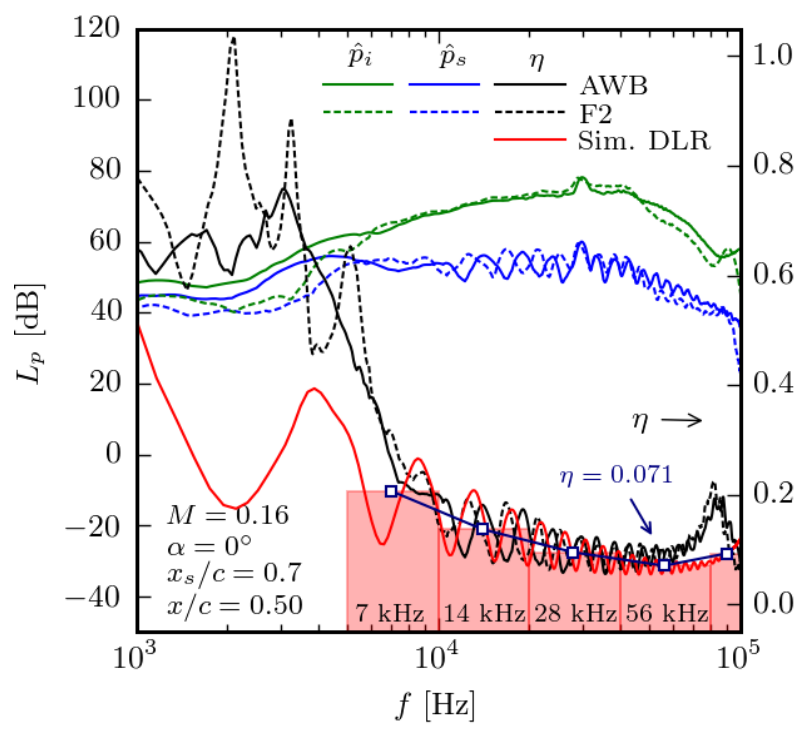

(b) Spectra

Fig. 17 Laser sound source in AWB vs F2, $\alpha=0^{\circ}, M=0.16$ (a) Overall shielding level (b) Spectra of the incident, $\hat{p}_{i}$, and shielded, $\hat{p}_{s}$, pressures and of the shielding factor $\eta$, source position $x_{s} / c=0.7$, microphone position $x / c=0.5$. Octave bands and respective average value of $\eta$ shown by shaded area and empty square symbols in (b). 